\title{
COMPLICA OU DESCOMPLICA? REFLEXÕES SOBRE DECISÕES DE FAZER OU COMPRAR NA MAIOR STARTUP BRASILEIRA DE EDUCAÇÃO ${ }^{1}$
}

\author{
Rafael Carvalho Pereira ${ }^{2}$ \\ Fernando Oliveira de Araujo ${ }^{3}$
}

http://dx.doi.org/10.1590/1413-2311.164.61819

\begin{abstract}
RESUMO
O caso narra a trajetória da startup de educação Descomplica desde a idealização da empresa até o seu crescimento, evidenciando os dilemas organizacionais relacionados às decisões de fazer ou comprar (the make-buy decision) em seus processos-chave, com vistas a conciliar um crescimento exponencial de clientes com atenção especial na qualidade dos serviços prestados. A situação narrada acontece entre os anos de 2010 e 2012, tendo o fundador da empresa Marco Fisbhen como o principal personagem deste caso. O referido empreendedor, com a experiência acumulada de 17 anos ministrando aulas em cursinhos pré-vestibulares presenciais, resolveu gravar suas aulas e disponibiliza-las online com foco no Exame Nacional do Ensino Médio (ENEM), visando dar escala ao serviço prestado, utilizando a internet como principal mecanismo de distribuição. Os desafios enfrentados por Fisbhen e sua organização nascente na obtenção de investimentos também são tratados no caso, analisando os fatores positivos e negativos das opções de aportes financeiros disponíveis para a empresa. Como instrumento de ensino, o caso foi concebido para apoiar reflexões sobre empreendedorismo, gestão de negócios e de inovação em cursos de graduação e pósgraduação, proporcionando a discussão e o julgamento de estudantes sobre as vantagens e desvantagens de cada uma das situações narradas no documento. Como objetivo secundário, o caso oferece aos leitores uma abordagem sobre ferramentas para formatação do negócio, desenvolvimento e validação de ideias, inspiradas nos ensinamentos de Eric Ries e outros autores sobre startups e startups enxutas (lean startups). O caso ainda contempla uma série de informações sobre a educação no cenário brasileiro, destacando a tendência e aumento do crescimento do público-alvo da referida empresa com a unificação do ENEM em 2009.
\end{abstract}

Palavras-chave: Decisões de Fazer ou Comprar. Competências Centrais. Integração Vertical.Startup Enxuta, Descomplica.

\section{TO COMPLICATE OR TO UNCOMPLICATE? REFLEXIONS ABOUT MAKE-BUY DECISIONS IN THE LARGEST BRAZILIAN EDUCATION STARTUP}

\begin{abstract}
The case recounts the path taken by the educational startup Descomplica (uncomplicate in english), from the original idea that created the company until its growth, highlighting the
\end{abstract}

\footnotetext{
${ }^{1}$ Recebido em 24/01/2016; aprovado em 03/04/2017.

${ }^{2}$ Universidade Federal Fluminense - rafaelcarvalho@id.uff.br.

${ }^{3}$ Universidade Federal Fluminense - fernandoaraujo@id.uff.br.
} 
organizational dilemmas related to the make-buy decisions in its key processes, aiming to combine the exponential growth in client-base with special attention to quality in the services provided. The situation described takes place between 2010 and 2012, and has the company's founder Marco Fisbhen as the main character in this case. The entrepreneur, who boasted a 17-year experience in administering live classes in college exam preparatory courses, decided to record his lectures and make them available online with the National Secondary Education Exam (known by its Portuguese acronym "ENEM") in mind, aiming to scale the service provided by using the internet as the main distribution media. The challenges faced by Fisbhen and his organization beginning with the acquisition of investments, are also discussed in the case, which analyzes the pros and cons of the financing options made available to the company. As a teaching tool, the case was devised to support entrepreneurial ideals, business management, and innovation in undergraduate and graduate courses, promoting the discussion and evaluation among students of the advantages and disadvantages of each of the situations described in the document. As a secondary goal, the case offers to readers an introduction to tools for business structuring, development, and the validation of ideas, inspired by the teachings of Eric Ries and other authors of literature on startups and lean startups. The case additionally provides a great array of information about education in the Brazilian landscape, highlighting its tendency to increase the growth of the target market for the company in question, with the standardization of ENEM in 2009.

Keywords: Make-Buy Decisions. Core Competencies. Vertical Integration. Lean Startup. Descomplica.

\section{¿CON COMPLICACIONES O SIN COMPLICACIONES? REFLEXIONES SOBRE LA DECISIÓN DE HACER O COMPRAR EN LA MAYOR STARTUP BRASILERA DE EDUCACIÓN}

\section{RESUMEN}

El estudio de caso cuenta la trayectoria de la startup de educación de nombre Descomplica, desde la idealización de la empresa hasta su crecimiento, mostrando los problemas organizacionales relacionados a las decisiones de hacer o comprar (the make-buy decision) para sus procesos llaves, debido al crecimiento exponencial de sus clientes, dando atención especial a la calidad de los servicios entregados. La situación mostrada de la startup sucede entre los años de 2010 hasta 2012, teniendo a Marco Fisbhen fundador de la empresa, como principal actor de este caso. El referido emprendedor tiene una experiencia acumulada de 17 años dando clases en cursos preuniversitarios, debido a esta experiencia Marco decidió gravar sus clases para que así las personas las asistieran de forma online, el foco de estas clases era para el examen nacional de enseño medio de Brasil. Los desafíos enfrentados por Fisbhen son tratados en el caso, analizando los factores positivos y negativos de las opciones de aportes financieros disponibles para la empresa. Como herramienta de aprendizaje, este caso fue creado para apoyar las reflexiones sobre las acciones de los emprendedores, gestión de negocios y innovación en los cursos de graduación y de post graduación, entregando discusiones para el juzgamiento de los estudiantes sobre las ventajas y desventajas en cada una de las situaciones narradas en el documento. Como objetivo segundario el caso entrega a los lectores un abordaje sobre las herramientas para la estructuración de negocios, desarrollo y validación de ideas inspiradas en los enseñamientos de Eric Ries y otros autores sobre las startups y startup limpias (lean startups). El caso también entrega varias informaciones sobre 
la educación en Brasil, destacando las tendencias y aumento del crecimiento del público objetivo de la empresa discutida con su unificación con el examen nacional de enseño medio (ENEM) en 2009.

Palabras-clave: Decisiones de Hacer o Comprar. Competencias Centrales. Integración Vertical. Startup Limpias. Descomplica.

\section{INTRODUÇÃO}

“Quero dar escala à educação!”, essa foi a frase proferida pelo fundador da startup ${ }^{4}$ Descomplica, Marco Fisbhen, quando pensou em gravar suas aulas de cursinho pré-vestibular e disponibilizá-las online. A Descomplica é uma empresa de educação e tecnologia que através de seu website (www.descomplica.com.br), fornece videoaulas preparatórias para o Exame Nacional do Ensino Médio (ENEM) e principais vestibulares do Brasil. O objetivo da empresa não é revolucionar a educação, mas, sim, resolver um problema: oferecer educação de qualidade a milhões de estudantes, democratizando o acesso às universidades.

O desejo de dar escala à educação não tinha o propósito de substituir o ensino nas escolas, mas de complementar a aprendizagem dos estudantes - muitos dos quais provenientes de realidades menos favorecidas em termos de renda e/ ou de oferta desse serviço qualificado em determinadas regiões do Brasil - com uma biblioteca de videoaulas referente a todos os assuntos abordados no ensino médio, ministrados por professores altamente especializados e reconhecidamente competentes. "E se a gente gravar todo o conteúdo do ensino médio em videoaulas e disponibilizar na web?" foi uma das hipóteses levantadas por Marco para entregar esse novo modelo de educação, usando a internet como estratégia de distribuição.

Professor de cursinhos pré-vestibulares há mais de 17 anos, Marco combinou sua experiência em ensinar com sua formação de engenheiro, viabilizando um modelo de negócio para dar escala à educação. Após apresentar sua ideia em alguns eventos de empreendedorismo, Marco iniciou em 2010 um projeto piloto com um aporte financeiro de $\mathrm{R} \$ 250.000,00$ pela associação privada de investimentos Gávea Angels.

Em 2011, em seu primeiro ano, a Descomplica contribuiu com o aprimoramento de mais de meio milhão de estudantes no Brasil. No ano seguinte foram mais de 1 milhão de estudantes e em 2013, mais de 3 milhões de estudantes acessaram a plataforma.

\footnotetext{
${ }^{4}$ Empresa nascente de base tecnológica e de inovação que possui um potencial de crescer exponencialmente (SEBRAE, 2011).
} 
Com um crescimento significativo e exponencial nos três primeiros anos, Marco e sua equipe perceberam um grande potencial de alavancagem da empresa em um horizonte de curto prazo. Para acelerar esse crescimento, a startup nascente precisava captar investimento para sua estruturação, visando a potencializar ainda mais o alcance para os estudantes do ensino médio e pessoas que pretendiam fazer o ENEM.

Entretanto, crescer de forma muito acelerada poderia transformar a cultura ágil de startup e depreciar a qualidade dos conteúdos educacionais da empresa. Marco tinha em mente que esse crescimento deveria ser de forma consistente, mantendo a cultura e identidade de sua empresa.

Seu grande desafio como CEO da Descomplica era o de definir até que ponto a empresa deveria fazer internamente ou terceirizar funções da cadeia operacional de sua atividade, mantendo sempre seus traços originais de uma startup ágil e inovadora, capaz de analisar os benefícios, riscos e custos associados a tais funções.

O dilema vivenciado pela nova organização estava intimamente associado a um fenômeno conhecido no âmbito acadêmico como "decisões de fazer ou comprar" (the makebuy decision). Tratam-se de dúvidas estratégicas dos gestores sobre o nível de integração vertical que devem assumir em suas operações. Em outras palavras, Descomplica apresentava um alto grau de incerteza na eficiência de seus processos devido a inovação proposta em dar escala à educação.

Com aportes financeiros obtidos e as grandes expectativas em relação ao negócio, Marco se via diante da responsabilidade de executar um projeto organizacional que pudesse atender aos crescimentos exponenciais almejados em relação à base de clientes da startup.

Vislumbrando um público potencial de 7 milhões de usuários no Brasil, Marco e seus diretores se viam diante de alguns dilemas sobre a governança das atividades-chave do seu novo empreendimento. Teria a nascente Descomplica a capacidade de internalizar todos os processos críticos do negócio? Valeria a pena subcontratar outras empresas para cuidarem de aspectos centrais da startup? Como atender com qualidade milhões de usuários diariamente?

\section{O PARADOXO DA EDUCAÇÃO BRASILEIRA NO SÉCULO XXI}

O ENEM foi desenvolvido em 1998 como forma de avaliar o desempenho dos alunos do ensino médio no Brasil, sendo considerado um marco importante para educação no século XXI. Uma proposta de reformulação do ENEM como forma de seleção unificada nos processos seletivos das universidades federais e estaduais foi apresentada para 2009 pelo 
Ministério da Educação. Com essa mudança, os processos seletivos de mais de 50 IES instituições de ensino superior no Brasil, incluindo Universidades e Institutos Federais, foram unificados em uma única avaliação, subdividida em quatro áreas de conhecimento, além da redação: linguagens e códigos, ciências humanas, ciências da natureza e matemática (http://portal.mec.gov.br/).

Em relação ao novo sistema de acesso ao ensino superior, as IES teriam a autonomia para adotar a nota do ENEM entre quatro possibilidades: como fase única, com o sistema de seleção unificada; informatizado e online; como primeira fase; combinado com o vestibular da instituição ou como fase única para as vagas remanescentes do vestibular (http://portal.mec.gov.br/).

Com isso, o número de inscritos no exame dobrou em 5 anos a partir de 2009, conforme ilustra o Gráfico 1.

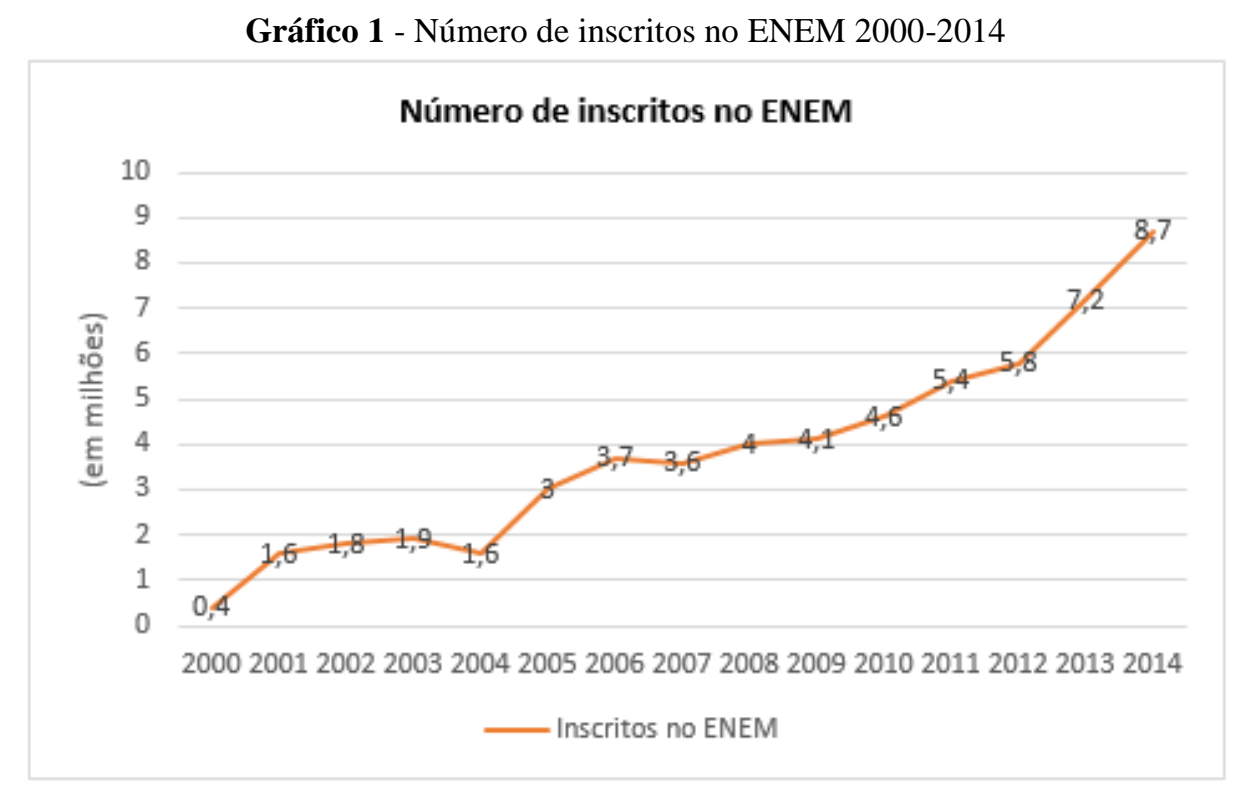

Fonte: disponível em http://blog.planalto.gov.br/.

Em contrapartida ao aumento significativo da demanda pelo Exame, o crescimento do número de estudantes matriculados no ensino médio, principal público do ENEM, estagnouse no período. Segundo o MEC (http://portal.inep.gov.br/basica-censo-escolar-sinopsesinopse, acesso em 12/08/2015 às 17h20), os matriculados no ensino médio cresceram 1,30\% de 2000 até 2014. Em números absolutos, houve um aumento de 8.192.948 para 8.300.189 estudantes. O Gráfico 2 ilustra a evolução das matrículas de estudantes do ensino médio no Brasil. 
Gráfico 2 - Número de matrículas no ensino médio 2000-2014

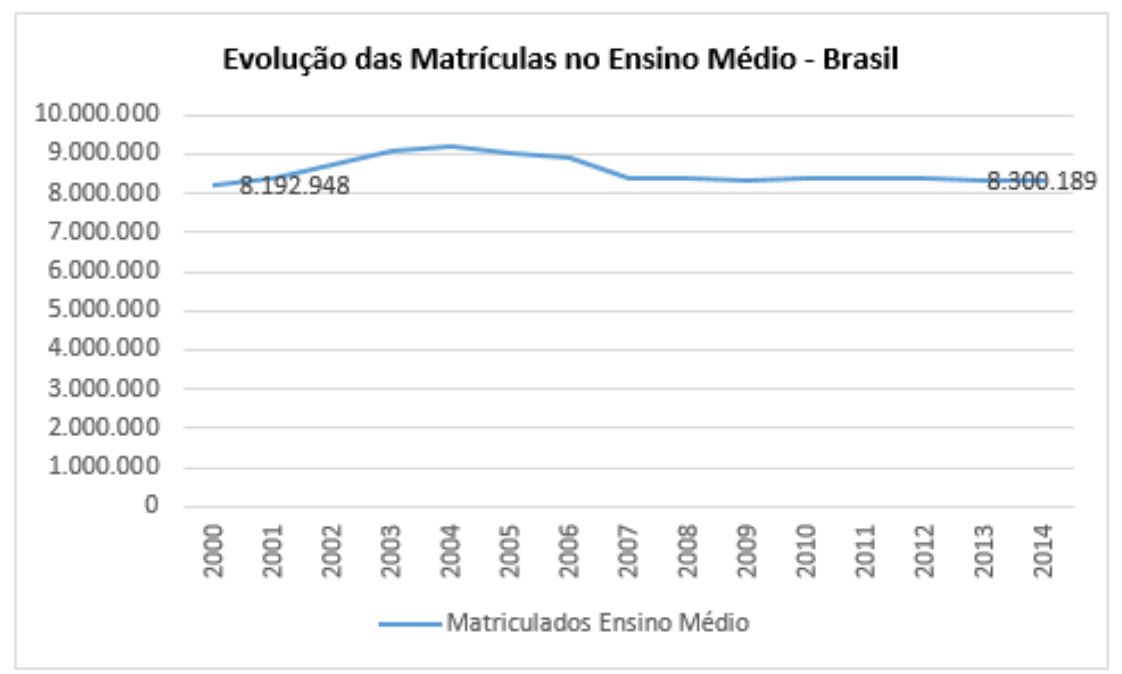

Fonte: disponível em http://inep.gov.br.

O sonho do estudante em ingressar em uma IES pública fica mais distante considerando-se a disponibilidade de vagas (menos de 2 milhões, em 2013). Entre 2000 e 2013, o crescimento da oferta de cursos em IES privadas foi três vezes maior do que o crescimento da oferta de cursos em IES pública, como se pode observar no Gráfico 3.

Esse aumento desproporcional de oferta vagas entre IES privadas e públicas desfavorece os candidatos em situação de vulnerabilidade social e econômica. A Faculdade de Medicina São Leopoldo em Campinas, por exemplo, demanda investimentos, por aluno, de mais de $\mathrm{R} \$ 140.000,00$ por ano. As mensalidades dos cursos de medicina, tradicionalmente mais caros, variam de 3 mil a 11 mil, tornando-se inviáveis para milhares de candidatos (escolasmedicas.com.br, acessado em 30/08/2015 às 18h40).

Adicionalmente, o ingresso em instituições públicas de ensino requer um desempenho melhor no ENEM. A preparação para o exame exige uma boa escolaridade, usualmente associadas a estudos complementares em cursos de pré-vestibulares de qualidade.

O Índice de Desenvolvimento de Educação Básica (IDEB) foi criado em 2007 para aferir, em uma escala de 1 a 10, dois conceitos de qualidade da educação básica no Brasil: aprovação e média do desempenho dos estudantes em língua portuguesa e matemática. Conforme ilustra o Gráfico 4, pode-se observar a diferença de desempenho entre escolas públicas e privadas.

Muitos estudantes que almejam um curso mais concorrido ou não se sentem preparados para o exame optam por cursos pré-vestibulares cujas mensalidades variam de $\mathrm{R} \$ 200,00$ até $\mathrm{R} \$ 1.500,00$ por mês (http://guiadoestudante.abril.com.br/, acesso em 
30/08/2015 às 19h05).

Gráfico 3 - Número de matrículas no ensino superior 1980-2013

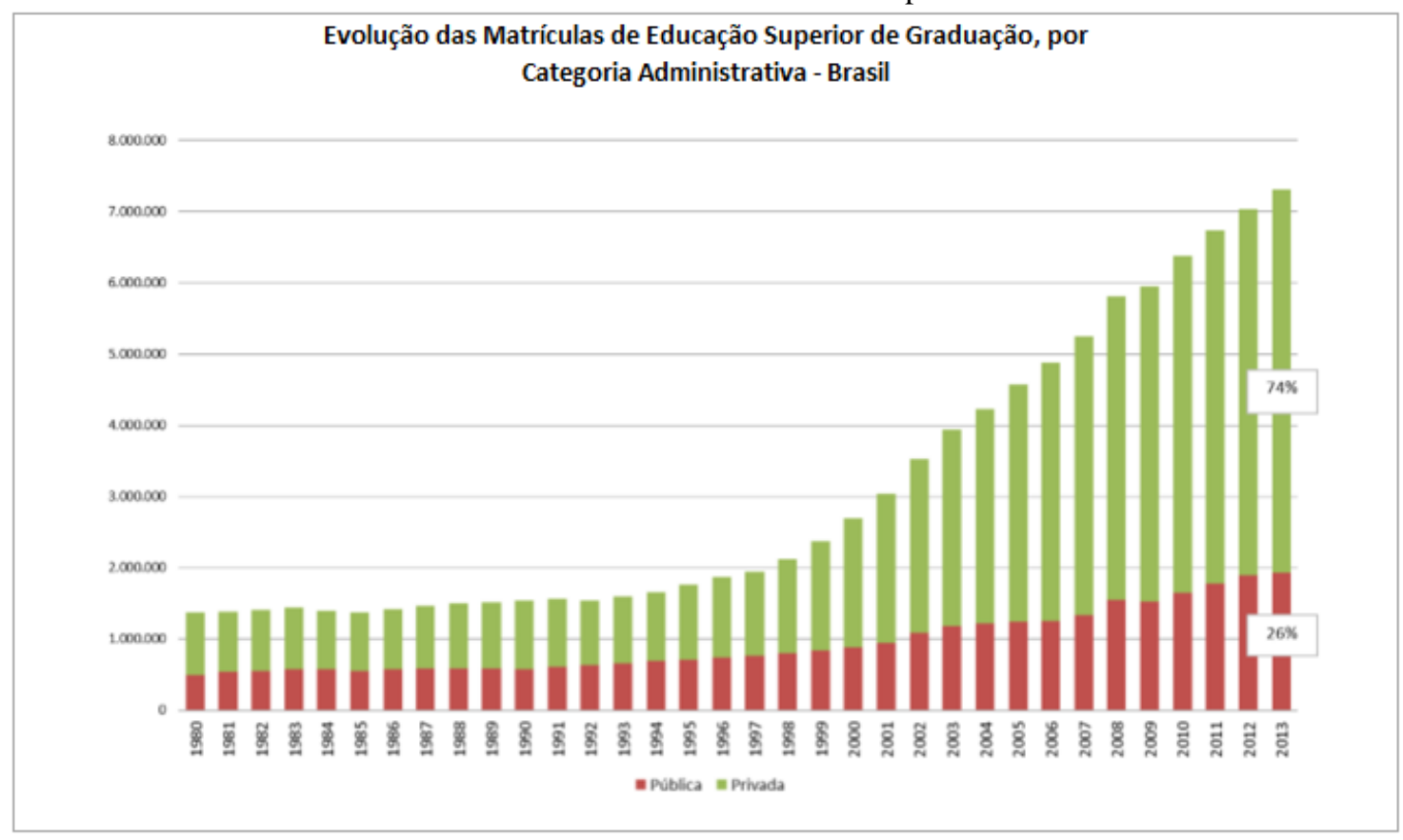

Fonte: disponível em http://inep.gov.br.

Esse investimento na preparação para o ENEM, entendido como importante, sobretudo, para ter oportunidade de ingresso nos cursos mais concorridos de instituições bem avaliadas, acaba sendo inviável para inúmeros estudantes, tornando o acesso aos cursos de graduação em IES públicas, pendente às classes sociais mais favorecidas.

Gráfico 4 - IDEB por categoria administrativa - histórico desde 2007 e projeção para 2021

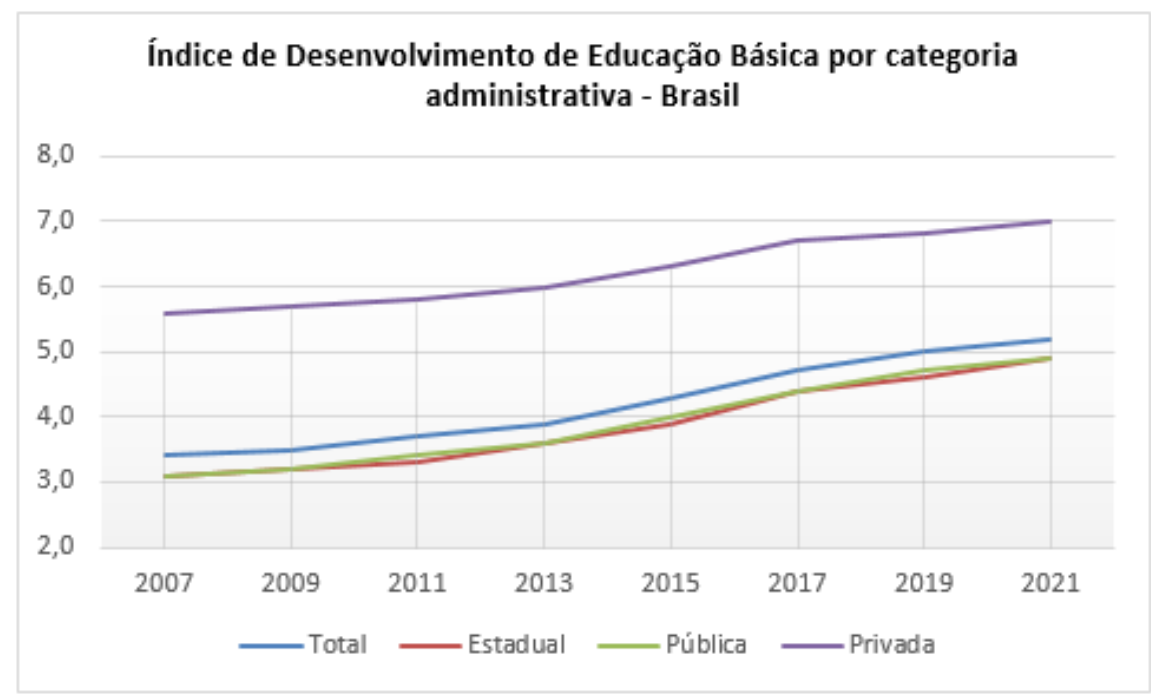

Fonte: disponível em http://portal.inep.gov.br/web/portal-ideb. 


\section{UM MODELO DE NEGÓCIO ATRAENTE}

A ideia de dar escala ao ensino através da internet foi inicialmente testada por Marco em 2010 ao gravar suas próprias aulas através de uma câmera e seu conhecimento básico em edição de vídeos. Ao posta-las no YouTube, foi possível notar o crescimento nas visualizações e principalmente, feedbacks positivos de diversos espectadores (Figura 1).

Figura 1 - Videoaula publicada no Youtube

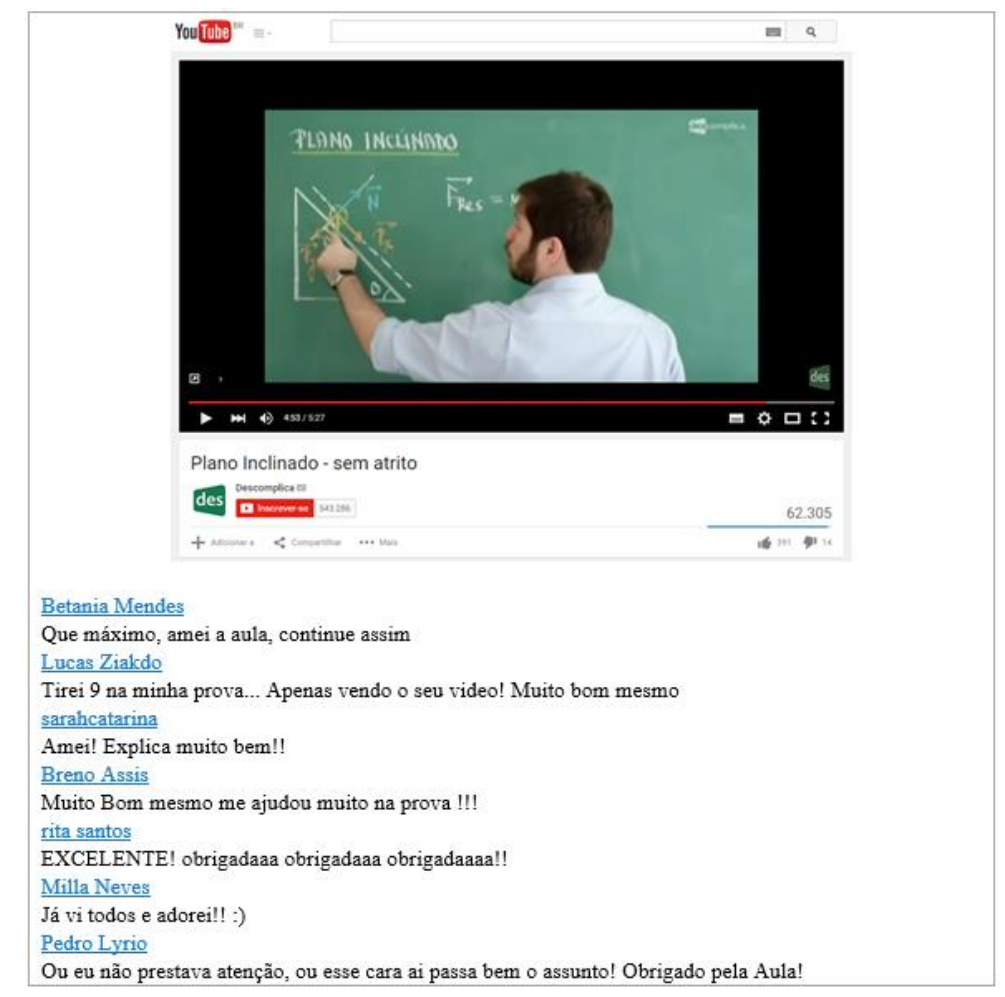

Fonte: YouTube.

Como forma de adquirir um aporte financeiro para investir em sua ideia, Marco começou a elucubrar sobre modelos de negócio que pudessem atrair investidores. Depois de reflexões com mentores, Marco adotou o Business Model Canvas para apoiá-lo na formatação do seu plano de negócio da futura organização (Figura 2).

O modelo de receita definida da Descomplica, conhecido como freemium - utilizado por diversas empresas de tecnologia como o Spotify e Dropbox - fornece gratuitamente o seu serviço e após certo tempo e/ ou novas funcionalidades, é necessário pagar uma mensalidade. A parte gratuita, chamada de degustação, revela-se como uma estratégia de marketing para converter o usuário em cliente. 
Figura 2 - Business Model Canvas

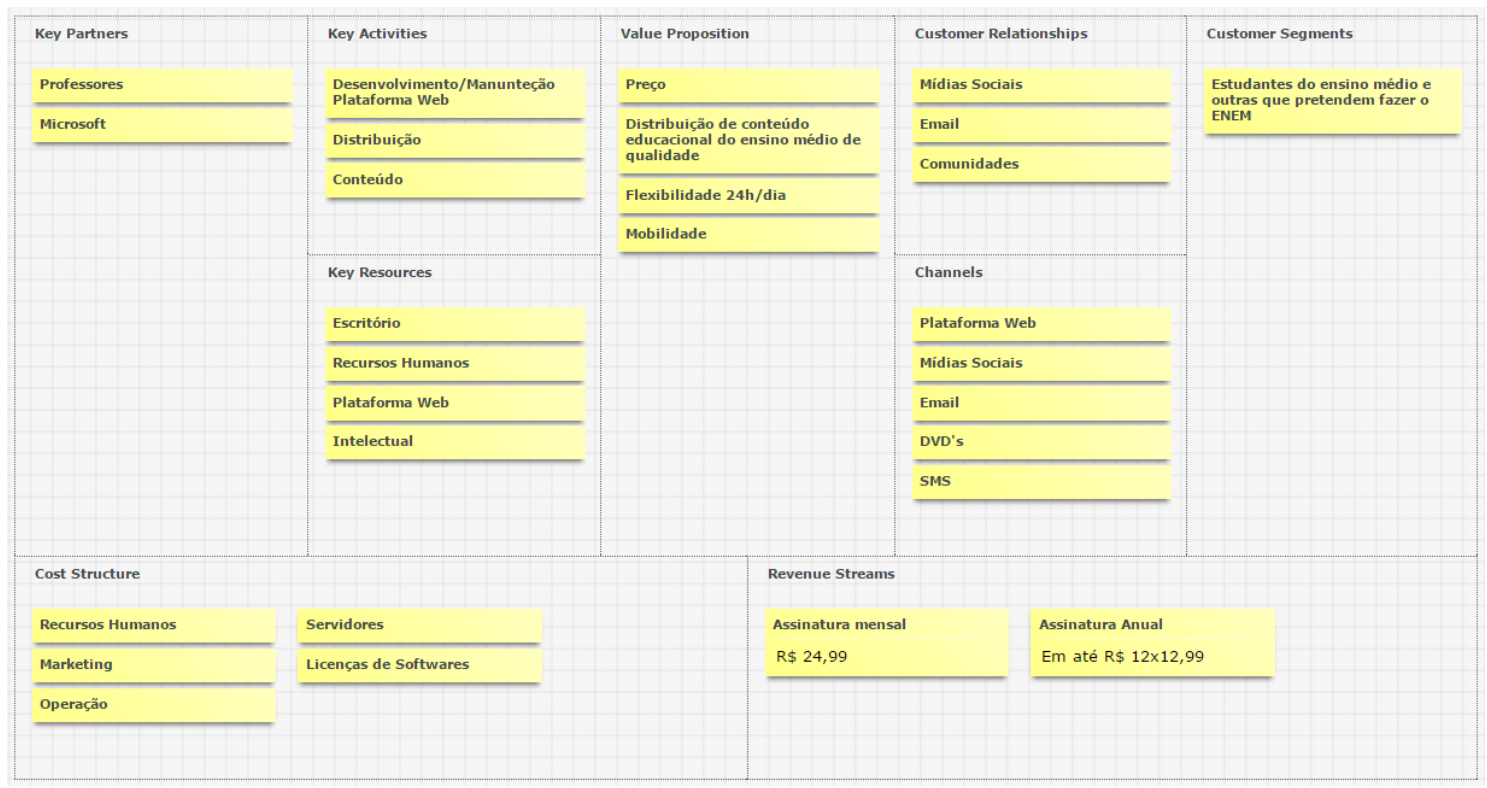

Fonte: Descomplica (2011).

Por meio desse modelo de receita, a Descomplica apostou na flexibilidade do usuário de poder assistir aulas online em qualquer lugar e a qualquer hora através da internet, em que o usuário teria um conteúdo gratuito limitado do ensino médio e caso tivesse interesse em acessar todo o conteúdo e novas funcionalidades, poderia efetuar o pagamento online através de boleto bancário ou cartão de crédito por um preço bastante acessível em relação aos prévestibulares presenciais. A Figura 3 ilustra a página de assinatura da Descomplica.

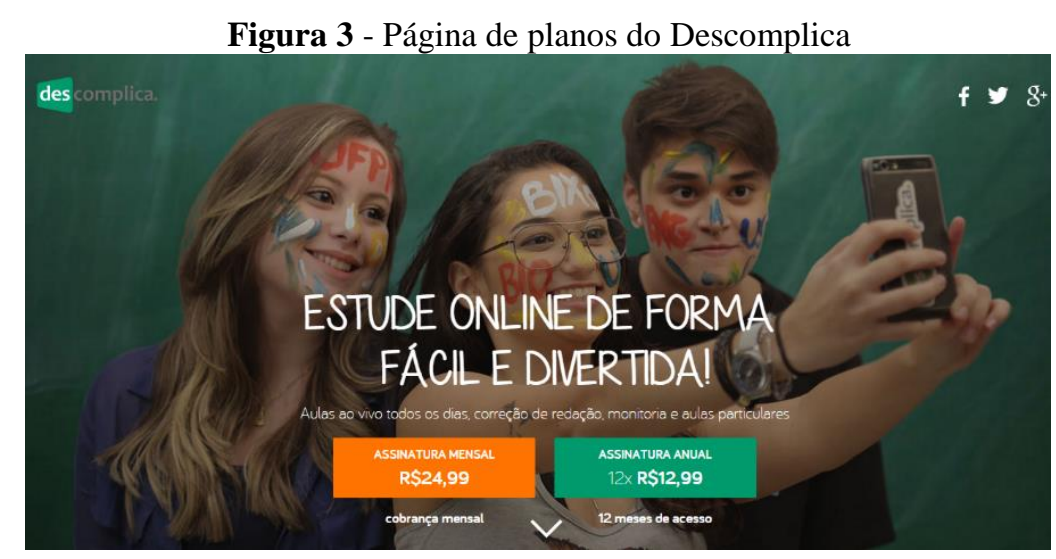

Fonte: disponível em $\underline{w w w . d e s c o m p l i c a . c o m . b r / a s s i n a t u r a . ~}$

Assim, com a expectativa de receita anual por cliente em torno de $\mathrm{R} \$ 100,00$, multiplicado por 100, 1000, 10.000 ou até 7.000 .000 de potenciais clientes, sendo renovado todo ano pela nova aplicação do ENEM, despertou interesse em investidores que fecharam seu primeiro aporte de investimento milionário no valor de US\$2.000.000,00 no segundo 
semestre de 2012 por fundos americanos (Disponível em: http://techcrunch.com/2012/12/19/descomplica-nabs-2m-from-peter-thiel-socialcapital-500startups-more-to-help-brazil-prep-for-college/. Acesso em 10/09/2015 às 20h15).

Com o propósito de entregar conteúdo a milhões de estudantes e a estratégia do plano de negócio definida, Marco recrutou uma equipe de desenvolvedores para remodelar e reestruturar seu produto: uma plataforma de vídeo-aulas disponível em www.descomplica.com.br.

Em diversos brainstormings, Marco e seus conselheiros, idealizaram as características principais de sua empresa para aumentar a sua taxa de sucesso, visto que era algo totalmente incerto perante um mercado que até então não havia um concorrente direto. Como forma de se diferenciar de alguns concorrentes indiretos, como Coursera (EUA) ou Khan Academy (EUA), Marco se debruçou sobre quatro aspectos fundamentais para que a Descomplica consolidasse uma identidade própria. O Quadro 1 sumariza os conceitos propostos pelo empreendedor para o seu negócio.

\begin{tabular}{|c|c|}
\hline \multicolumn{2}{|c|}{ Quadro 1 - Identidade do Descomplica } \\
\hline Conteúdo & $\begin{array}{l}\text { Divertidos: de forma descontraída } \\
\text { Simples: vídeos curtos de até } 7 \text { minutos } \\
\text { Acessível: preço baixo } \\
\text { Conectado: digital } \\
\text { Educativo: ensinando de forma clara }\end{array}$ \\
\hline Distribuição & Garantia de entrega de conteúdo a todos \\
\hline Engajamento & Recorrência do uso pelos alunos \\
\hline Performance & Aprendizado e bons resultados nas avaliações \\
\hline
\end{tabular}

\section{A VALIDAÇÃO DO MODELO DE NEGÓCIO}

O processo de validação da Descomplica foi baseado na metodologia Lean Startup, de Eric Ries (2011), que tinha como propósito recolher feedbacks de primeiros usuários e analisar métricas de crescimento para aprimorar cada vez mais o seu produto. O MVP (minimum viable product), ou seja, o produto mínimo comercializável da Descomplica foi lançado em 2011, sendo um website simples que concentrava todo o conteúdo audiovisual de educação para o ENEM. Após lançado, iniciou-se o ciclo de evolução conhecido como construir-medir-aprender (Figura 4). 
Figura 4 - Ciclo construi-medir-aprender - Lean Startup

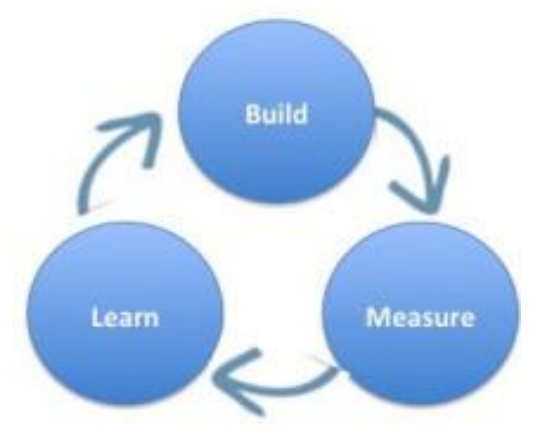

Fonte: https://endeavor.org.br/construir-medir-aprender/.

O referido ciclo consiste em idealizar uma nova funcionalidade ou característica para o produto (build), proveniente de feedbacks, insights das métricas analisadas ou brainstorming de sua equipe (measure), conforme Quadro 2. Nesse caso, a equipe da Descomplica observava a reação dos usuários imediatamente após construir uma nova solução, ou seja, codificar se for uma funcionalidade do site ou a execução de uma nova característica de produto, para depois medir os resultados de aceitação dessa nova iteração.

Nos casos observados no Quadro 2, os aprendizados foram validados, justificando a implementação, de forma à melhoria do produto. Em caso negativo, Marco e sua equipe declinavam da implementação e recomeçava o ciclo para desenvolvimento de novas características ou funcionalidades, respeitando sempre um tempo de uma a duas semanas entre suas iterações para garantir seu desenvolvimento ágil e uma inovação contínua de produto. O Quadro 3 sumariza alguns dos aprendizados invalidados de Marco e sua equipe em 2011.

Quadro 2 - Aprendizados validados que foram incorporados na Descomplica

\begin{tabular}{|c|c|c|c|}
\hline $\begin{array}{r}\text { Tipologia do } \\
\text { Experimento }\end{array}$ & Experimento & Feedback de usuários & Análise de métricas \\
\hline $\begin{array}{l}\text { Conteúdo } \\
\text { (videoaulas) }\end{array}$ & Vídeos de até 7 minutos & $\begin{array}{l}\text { Menos cansativo, mais } \\
\text { focado no assunto }\end{array}$ & $\begin{array}{c}\text { Diminuiu a taxa de abandono dos } \\
\text { vídeos e aumentou a média de } \\
\text { visualização completa das } \\
\text { videoaulas. }\end{array}$ \\
\hline $\begin{array}{l}\text { Distribuição } \\
\text { (site) }\end{array}$ & $\begin{array}{l}\text { Criação de plano de } \\
\text { estudo por semanas }\end{array}$ & $\begin{array}{c}\text { Melhorou a organização } \\
\text { dos conteúdos e forma } \\
\text { de aprendizado }\end{array}$ & $\begin{array}{l}\text { Diminuiu a taxa de abandono do } \\
\text { site e diminuição do número de } \\
\text { requisições no SAC com dúvidas } \\
\text { sobre o uso do produto. }\end{array}$ \\
\hline $\begin{array}{l}\text { Engajamento } \\
\text { (site) }\end{array}$ & $\begin{array}{c}\text { Login integrado com } \\
\text { Facebook }\end{array}$ & $\begin{array}{l}\text { Simplificação no } \\
\text { cadastro e login de } \\
\text { usuários }\end{array}$ & $\begin{array}{l}\text { Aumentou a taxa de cadastros, } \\
\text { aumentou o número absoluto de } \\
\text { cadastros. }\end{array}$ \\
\hline
\end{tabular}

Fonte: elaborado pelos autores. 
Quadro 3 - Aprendizados invalidados e não incorporados na Descomplica

\begin{tabular}{|l|c|c|c|}
\hline \multicolumn{1}{|c|}{$\begin{array}{c}\text { Tipologia do } \\
\text { Experimento }\end{array}$} & Experimento & Feedback de usuários & Análise de métricas \\
\hline $\begin{array}{l}\text { Conteúdo } \\
\text { (videoaulas) }\end{array}$ & Criar módulo de Espanhol & Positivo & $\begin{array}{c}\text { Baixo número de } \\
\text { visualizações e demanda } \\
\text { de estudantes. }\end{array}$ \\
\hline Distribuição & $\begin{array}{c}\text { Gravação e distribuição de } \\
\text { conteúdos por DVDs }\end{array}$ & $\begin{array}{c}\text { Dificuldade de acesso e } \\
\text { falta de atualização no } \\
\text { conteúdo. }\end{array}$ & $\begin{array}{c}\text { Vendas realizadas, porém } \\
\text { com falhas de logística. }\end{array}$ \\
\hline $\begin{array}{l}\text { Conteúdo } \\
\text { Revista sobre o } \\
\text { ENEM) }\end{array}$ & $\begin{array}{c}\text { Criar um aplicativo com } \\
\text { informações e conteúdos } \\
\text { para o ENEM }\end{array}$ & $\begin{array}{c}\text { Grande fricção para ter } \\
\text { que baixar o aplicativo } \\
\text { apenas para leitura. }\end{array}$ & $\begin{array}{c}\text { Downloads abaixo do } \\
\text { esperado e baixo } \\
\text { engajamento no } \\
\text { aplicativo. }\end{array}$ \\
\hline
\end{tabular}

Fonte: elaborado pelos autores.

Após diversas iterações e novas implementações, o MVP foi se transformando em uma plataforma online robusta e com alta aceitação pelos seus usuários. O crescimento orgânico e consistente já era evidente no início de 2012, saindo de uma posição de startup neófita para uma posição de alavancagem do negócio.

Testes experimentais com objetivo de melhorias foram realizados no site, durante períodos específicos de tempo, dividindo a audiência pela metade: uma parte (controle) tinha acesso às informações normais e a outra parte acessava o site com pequenas alterações ativadas para analisar o comportamento dos usuários nesse período de teste, em cada experimento. Conhecido como teste A-B, esse procedimento foi essencial para maximizar indicadores financeiros como:

- número de conversões ${ }^{5}$ absolutas aprovadas (vendas confirmadas de assinaturas);

- taxa de aprovação de conversões absolutas (conversões aprovadas/ conversões totais);

- taxa de conversões (conversões absolutas/ cliques na página de pagamentos);

- receita total;

- receita esperada por um cliente (lifetime value).

O Quadro 4 apresenta exemplos de testes realizados para otimização do site em 2012. A taxa de significância estatística ${ }^{6}$ utilizada foi de $95 \%$.

\footnotetext{
${ }^{5}$ Conversão: efetivação de uma assinatura do site, representando a obtenção de um usuário pagante.

${ }^{6}$ Taxa de significância estatística é o nível de confiança de um resultado, que seja improvável de ter ocorrido por acaso.
} 
Quadro 4 - Testes A-B

\begin{tabular}{|c|c|}
\hline $\begin{array}{c}\text { Testes A-B } \\
\end{array}$ & Resultado \\
\hline $\begin{array}{l}\text { Preço R\$ 12,99 ou R\$ 9,99 mensal } \\
\text { (questionamento: qual preço final maximiza a } \\
\text { receita?) }\end{array}$ & $\begin{array}{l}\text { O teste de preço varia de acordo com a sazonalidade do } \\
\text { ano. Por isso, é realizado constantemente e a variação } \\
\text { que apresenta uma maior taxa de conversão e receita, } \\
\text { permanece. Aumentar o preço final não implica no } \\
\text { aumento de receita, pois o número de conversões, taxa } \\
\text { de conversão e a receita proveniente das conversões } \\
\text { podem justificar um preço final menor, com uma receita } \\
\text { maior no período. }\end{array}$ \\
\hline $\begin{array}{l}\text { Texto e cor do botão de assinatura } \\
\text { (questionamento: que texto e cor do botão maximiza } \\
\text { a receita?) }\end{array}$ & $\begin{array}{l}\text { A cor do botão de compra laranja em maior contraste } \\
\text { com o site e o texto do botão "Eu quero passar", mais } \\
\text { lúdico, aumentou em } 15 \% \text { a receita em relação à } \\
\text { variações com cor verde e texto "Assine Já". }\end{array}$ \\
\hline $\begin{array}{l}\text { Remover menu da página de assinatura } \\
\text { (questionamento: eliminar pontos de distração na } \\
\text { página de assinatura maximiza a receita?) }\end{array}$ & $\begin{array}{l}\text { A variação que não apresentava menu na página de } \\
\text { assinatura gerou um aumento de } 20 \% \text { na receita. }\end{array}$ \\
\hline $\begin{array}{l}\text { Cadastro obrigatório ou facultativo } \\
\text { (questionamento: obrigar o cadastro depois de } \\
\text { visualizar uma vídeo-aula aumenta a taxa de } \\
\text { cadastros e cadastros diários?) }\end{array}$ & $\begin{array}{l}\text { Um popup de cadastro, sem a opção de sair (clicar no } \\
\text { "X"), no momento que o usuário visualiza um vídeo } \\
\text { aumentou a taxa de cadastro em } 90 \% \text { em relação ao } \\
\text { popup de cadastro com a opção de sair ("X" disponível). } \\
\text { Forçar o cadastro para uso free, quase que duplica a taxa } \\
\text { de cadastro. }\end{array}$ \\
\hline
\end{tabular}

Fonte: elaborado pelos autores.

\section{PREPARAR PARA DECOLAR}

Após um crescimento significativo nas visualizações das videoaulas postadas por Marco e a alta aceitação de seu projeto de website lançado em 2011, com investimentos ainda na casa de dezenas de milhares, chegava a hora de pensar em quão rápido seria o crescimento nos próximos anos se o valor de investimento chegasse ao patamar dos milhões.

A decisão de aumentar o valor de investimento veio após consolidarem um produto de mercado definido, também conhecido como product-market fit. Neste momento, a startup mapeou seus canais de aquisição de clientes e traçou estratégias de crescimento para reter ainda mais seus usuários. A Descomplica estaria em transição da fase de tração ${ }^{7}$, a qual já era notável o crescimento orgânico de acessos, para fase de crescimento, cujo objetivo principal era a aquisição de novos clientes.

Marco sabia que poderia investir parte de sua verba em aquisição de clientes, mas a retenção de seus usuários em sua plataforma seria uma consequência de um produto de qualidade. Conhecido como custo por aquisição (CPA), esta métrica representava o valor

\footnotetext{
7 Tração: Fase em que o produto ou serviço de uma startup é validado como atrativo aos seus clientes, aumentando as métricas de crescimento (receita, cadastros, downloads...) continuamente e de forma sustentável. O público-alvo é definido e nota-se uma taxa de retenção de clientes, através da satisfação e do interesse pelo consumo (BAULFOR, 2013).
} 
investido em marketing de mídias pagas para se adquirir um cliente. Combinando com a métrica de receita esperada por cliente (LTV), Marco e seus diretores tinham a oportunidade de dar escala não só a educação, mas também à lucratividade da empresa, se o CPA fosse menor do que o LTV. Portanto, Marco iniciou em 2012 a busca por um investimento de maior volume, analisando alguns fatores importantes representados no Quadro 5.

Quadro 5 - Opções de investimento para capitalização da Descomplica

\begin{tabular}{|l|c|c|c|}
\hline \multicolumn{1}{|c|}{ Opções / Fatores } & Tipo & Prós & Contras \\
\hline $\begin{array}{l}\text { Banco privado } \\
\text { nacional }\end{array}$ & Empréstimo & $\begin{array}{c}\text { Desenvolvimento } \\
\text { nacional }\end{array}$ & $\begin{array}{c}\text { Capital caro, endividamento, } \\
\text { burocracia, valor de aporte } \\
\text { baixo }\end{array}$ \\
\hline BNDES & Empréstimo & $\begin{array}{c}\text { Desenvolvimento } \\
\text { nacional, valor de aporte } \\
\text { alto }\end{array}$ & $\begin{array}{c}\text { Capital caro, endividamento, } \\
\text { burocracia }\end{array}$ \\
\hline $\begin{array}{l}\text { Programas de } \\
\text { Aceleração - Brasil }\end{array}$ & $\begin{array}{c}\text { Compra de participação } \\
\text { na empresa }\end{array}$ & $\begin{array}{c}\text { Desenvolvimento } \\
\text { nacional, experiência }\end{array}$ & $\begin{array}{c}\text { Burocracia, valor de aporte } \\
\text { baixo }\end{array}$ \\
\hline $\begin{array}{l}\text { Capital de risco }- \\
\text { Brasil }\end{array}$ & $\begin{array}{c}\text { Compra de participação } \\
\text { na empresa }\end{array}$ & $\begin{array}{c}\text { Desenvolvimento } \\
\text { nacional, experiência }\end{array}$ & $\begin{array}{c}\text { Média competitividade, Valor } \\
\text { de aporte mediano }\end{array}$ \\
\hline Opções / Fatores & Tipo & Prós & Contras \\
\hline $\begin{array}{l}\text { Capital de risco - } \\
\text { EUA }\end{array}$ & $\begin{array}{c}\text { Compra de participação } \\
\text { na empresa }\end{array}$ & $\begin{array}{c}\text { Experiência global, valor } \\
\text { de aporte alto, gosto por } \\
\text { risco }\end{array}$ & $\begin{array}{c}\text { Alta competitividade, } \\
\text { comunicação prejudicada }\end{array}$ \\
\hline
\end{tabular}

Fonte: elaborado pelos autores.

$\mathrm{O}$ aporte milionário seria para investir em basicamente quatro áreas estratégicas da empresa: recursos humanos; produção de conteúdo; tecnologia da informação e P\&D; marketing e mídia

\section{DECISÕES DE FAZER OU COMPRAR}

A terceirização de processos em uma organização é uma estratégia que vem sendo cada vez mais utilizada em empresas embrionárias8 por possuírem recursos limitados e necessidade de focalização de esforços em processos estratégicos que visam a aumentar sua chance de sucesso. Em muitas ocasiões, a terceirização de processos é a peça fundamental para dar escala a um negócio.

A integração vertical, geralmente, requer mais recursos e maior complexidade gerencial e organizacional. Processos mais estratégicos e que tenham um impacto de forma

\footnotetext{
${ }^{8}$ Empresas embrionárias: empresas em fase de implementação e organização de sua operação, em processo de validação do seu modelo de negócio e que não necessariamente esteja constituída.
} 
mais direta aos usuários finais costumam ser feitos internamente, porém a perpetuação da ineficiência é um risco iminente em caso de falha gerencial.

De acordo com Gutwald (1995), a decisão de fazer ou comprar pode ser classificada no âmbito organizacional sob as perspectivas: econômica, de custo de transação, estratégica e multidimensional. Tradicionalmente, a análise econômica de uma atividade é a mais utilizada para tomada de decisão, estudando-se o custo de desenvolvimento, aquisição e manutenção de uma atividade. Custo de transação é a análise do risco contratual nas relações comerciais com o parceiro, esperando-se que as atividades acordadas estejam sendo realizadas corretamente. A análise estratégica e multidimensional releva a vantagem competitiva que a atividade pode vir a agregar à empresa.

Segundo Serio e Sampaio (2001), para identificar as competências essenciais de uma empresa (core competencies) devem ser analisadas as capacidades da organização segundo dois critérios: a importância estratégica e a competência relativa no mercado. A importância estratégica é o questionamento se a atividade é ou não diferenciada em relação aos concorrentes, agregando valor ao produto final e sendo percebido pelos clientes. A análise da competência relativa é a comparação entre a empresa e as concorrentes no que se refere a custos, qualidade e processos.

A Figura 5 ilustra um dos modelos de análise sobre decisões de fazer ou comprar considerando duas variáveis: competência relativa e importância estratégica.

Figura 5 - Análise estratégica da decisão de fazer ou comprar

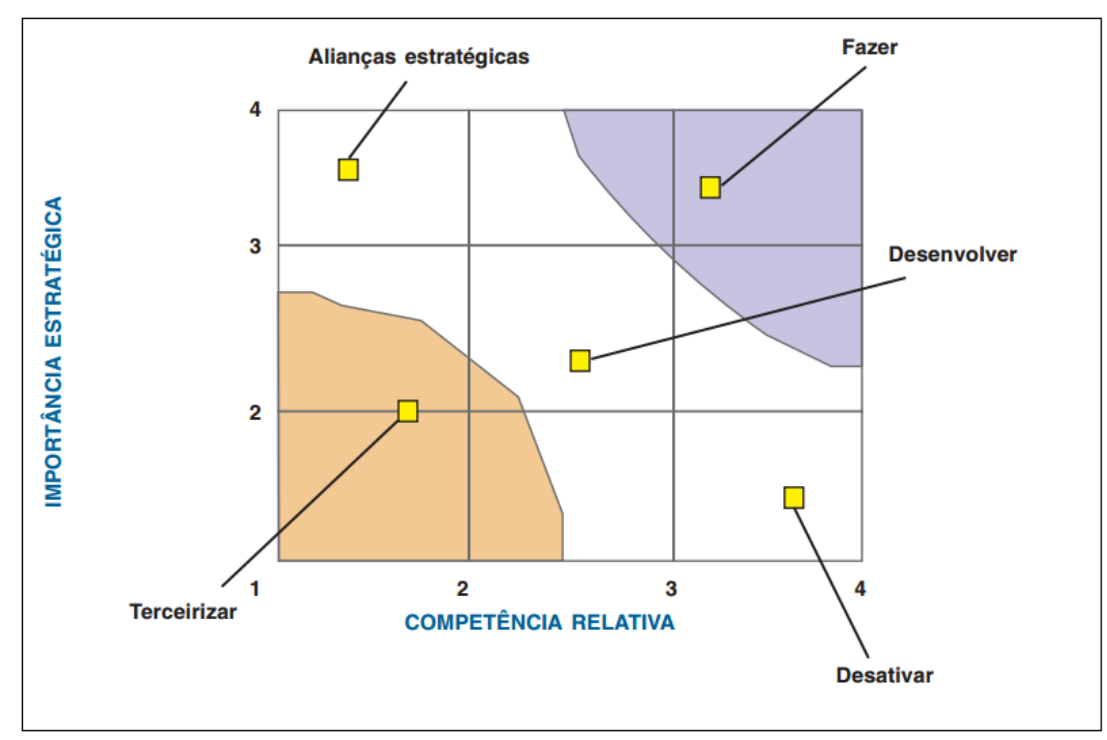

Fonte: Serio e Sampaio (2001).

Quinn e Hilmer (1994) sugerem algumas ações para identificar as competências 
centrais da organização:

- Focalizar em habilidades e conhecimentos, não em produtos ou funções. Os executivos precisam dar atenção às atividades que geram recursos intelectuais para empresa ou sistemas de gestão que promovam vantagem competitiva sustentável. Áreas tradicionais como engenharia, vendas e finanças não são mais competências centrais como no passado. Assim, espera-se desenvolver competências que envolvam atividades como design de produto ou serviço, criação de tecnologia, serviço ao cliente, logística, pesquisa e desenvolvimento.

- Desenvolver competência de longo prazo. Desenvolver e aperfeiçoar habilidades em áreas que os clientes irão valorizar no futuro.

- Limitar o número de competências. As empresas precisam desenvolver duas ou três habilidades críticas ao seu negócio, as quais exigem alto investimento de tempo e recurso que não deve ser desperdiçado com capacidades secundárias.

- Selecionar as melhores fontes. Analisar imperfeições no mercado e/ou gaps de conhecimento, nos quais os investimentos nos recursos intelectuais da empresa podem ser alavancados.

- Áreas onde a empresa pode dominar. As empresas costumam rentabilizar mais que seus concorrentes em áreas de atividades em que seu desempenho é mais eficiente.

- Focalizar as necessidades dos clientes. Uma competência central deve estar diretamente relacionada ao atendimento e serviço aos clientes.

- Incorporar sistemas organizacionais. A manutenção das competências não pode depender de algumas "estrelas" talentosas, cuja saída da empresa possa prejudicar o progresso da empresa.

Marco e sua equipe, ao desenvolverem um projeto organizacional capaz de justificar as altas somas necessárias à obtenção de um investimento milionário, precisavam definir antes de tudo, o que seria a empresa Descomplica nos próximos anos. Nessa definição de planejamento estratégico, a frase proferida por Marco "Seremos a maior plataforma de educação do mundo!” em julho de 2012, reforçou a ideia de constituir uma identidade própria e de referência no âmbito de educação online.

Alguns dias depois, em uma reunião, Marco e seus diretores levantaram alguns processos essenciais (Quadro 06) que a empresa Descomplica precisava definir a respeito de fazer ou comprar, para que se pudesse dar continuidade à proposta organizacional. Para contribuir no processo decisório, a equipe caracterizou as atividades de acordo com seis distintos critérios; (1) risco baixo, médio ou alto; (2) custo - valor efetivo da atividade no 
período de um ano; (3) gestão - passiva, ativa ou proativa; (4) conhecimento da equipe: baixo, médio ou alto; (5) complexidade técnica - baixo, médio ou alto; (6) eficiência- baixo, médio ou alto.

Os processos centrais destacados pela equipe precisavam ser analisados de forma a levar em consideração a missão e visão da empresa, aspectos positivos e negativos das decisões a serem tomadas, considerando-se também os seis critérios adotados. Teria a Descomplica capacidade de internalizar todos os processos críticos do negócio? Valeria a pena subcontratar outras empresas para cuidarem de aspectos centrais da startup? Com um modelo definido, estaria a empresa apta a atender com qualidade milhões de usuários diariamente? A internalização das atividades complica ou descomplica o desenvolvimento da organização?

Quadro 6 - Processos essenciais da Descomplica

(continua)

\begin{tabular}{|c|c|c|c|}
\hline Processo & Descrição & Terceirização & Internalização \\
\hline $\begin{array}{l}\text { Validação de } \\
\text { pagamentos } \\
\text { online }\end{array}$ & $\begin{array}{l}\text { Processar } \\
\text { informações } \\
\text { financeiras de } \\
\text { clientes como dados } \\
\text { de cartão e emissão } \\
\text { de boletos. }\end{array}$ & $\begin{array}{ll}\text { 1- } & \text { Risco: baixo } \\
\text { 2- } & \text { Custo: } 5 \% \text { da receita } \\
\text { bruta mensal } \\
\text { 3- Gestão: passiva } \\
\text { 4- Conhecimento da } \\
\text { equipe: alto } \\
\text { 5- Complexidade técnica: } \\
\text { baixo } \\
\text { 6- Eficiência: alta }\end{array}$ & $\begin{array}{l}\text { 1- Risco: alto } \\
\text { 2- Custo: desenvolvimento, } \\
\text { manutenção e segurança (equipe } \\
\text { TI: US\$ 25.000,00/ano) } \\
\text { 3- Gestão: proativa } \\
\text { 4- Conhecimento da equipe: } \\
\text { baixo, com necessidade de } \\
\text { capacitação } \\
\text { 5- Complexidade técnica: alta } \\
\text { 6- Eficiência: média }\end{array}$ \\
\hline $\begin{array}{l}\text { Hospedagem } \\
\text { do site }\end{array}$ & $\begin{array}{lr}\text { Utilização } & \text { de } \\
\text { servidores } & \text { para } \\
\text { manter } & \text { as } \\
\text { aplicações } & \text { online } \\
\text { 24h por dia } & \end{array}$ & $\begin{array}{ll}\text { 1- } & \text { Risco: baixo } \\
\text { 2- } & \text { Custo: US\$ } \\
& \text { 15.000,00/ano (parceria } \\
& \text { Microsoft) } \\
\text { 3- } & \text { Gestão: passiva } \\
\text { 4- } & \text { Conhecimento da } \\
\text { equipe: alto } \\
\text { 5- Complexidade técnica: } \\
\text { baixo } \\
\text { 6- Eficiência: alta }\end{array}$ & $\begin{array}{ll}\text { 1- } & \text { Risco: alto } \\
\text { 2- } & \text { Custo: investimento em } \\
& \text { servidores (ativos imobilizados: } \\
& \text { US\$ 10.000,00), manutenção e } \\
& \text { segurança (equipe TI: US\$ } \\
& 25.000,00 / \text { ano) } \\
\text { 3- } & \text { Gestão: proativa } \\
\text { 4- } & \text { Conhecimento da equipe: } \\
& \text { médio } \\
\text { 5- } & \text { Complexidade técnica: médio } \\
\text { 6- } & \text { Eficiência: baixa }\end{array}$ \\
\hline $\begin{array}{l}\text { Plataforma } \\
\text { Web de } \\
\text { conteúdo }\end{array}$ & $\begin{array}{l}\text { Utilização de um } \\
\text { website } \\
\text { gerenciamento de } \\
\text { conteúdo de vídeo } \\
\text { aulas }\end{array}$ & 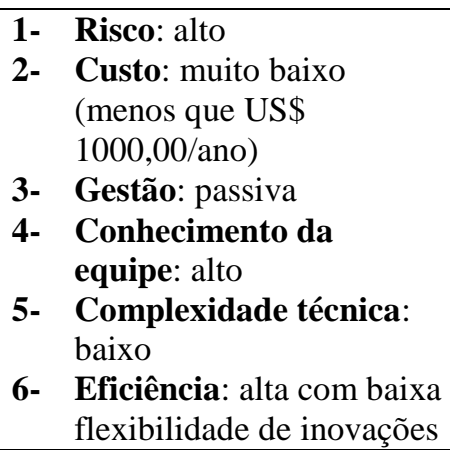 & $\begin{array}{l}\text { 1- Risco: médio } \\
\text { 2- Custo: desenvolvimento, } \\
\text { manutenção e segurança (equipe } \\
\text { TI: US\$ 50.000,00/ano) } \\
\text { 3- Gestão: proativa } \\
\text { 4- Conhecimento da equipe: alto } \\
\text { 5- Complexidade técnica: Alta } \\
\text { 6- Eficiência: alta }\end{array}$ \\
\hline
\end{tabular}


Quadro 6 - Processos essenciais da Descomplica

\begin{tabular}{|c|c|c|c|}
\hline Processo & Descrição & Terceirização & Internalização \\
\hline $\begin{array}{l}\text { Suporte ao } \\
\text { cliente e/ou } \\
\text { usuário }\end{array}$ & $\begin{array}{l}\text { Contato direto com } \\
\text { o cliente e/ou } \\
\text { usuário r por } \\
\text { mensagem em caso } \\
\text { de dúvidas, } \\
\text { pagamentos e } \\
\text { cancelamentos. }\end{array}$ & $\begin{array}{ll}\text { 1- } & \text { Risco: alto } \\
\text { 2- } & \text { Custo: (agência de suporte: } \\
& \text { US\$ 10.000,00/ano) } \\
\text { 3- } & \text { Gestão: passiva } \\
\text { 4- } & \text { Conhecimento da equipe: } \\
& \text { baixo } \\
\text { 5- Complexidade técnica: alto } \\
\text { 6- Eficiência: media }\end{array}$ & $\begin{array}{l}\text { 1- Risco: baixo } \\
\text { 2- Custo: (equipe de suporte: } \\
\text { US } \$ 40.000,00 / a n o \text { ) } \\
\text { 3- Gestão: proativa } \\
\text { 4- Conhecimento da equipe: } \\
\text { alto } \\
\text { 5- Complexidade técnica: } \\
\text { média } \\
\text { 6- Eficiência: alta }\end{array}$ \\
\hline $\begin{array}{l}\text { Gestão de } \\
\text { Mídias Sociais }\end{array}$ & $\begin{array}{l}\text { Interação/Suporte } \\
\text { com a comunidade } \\
\text { em redes sociais }\end{array}$ & $\begin{array}{ll}\text { 1- } & \text { Risco: baixo } \\
\text { 2- } & \text { Custo: Agência de } \\
& \text { Marketing (US\$ } \\
& 10.000,00 / \text { ano) } \\
\text { 3- Gestão: passiva } \\
\text { 4- Conhecimento da equipe: } \\
\text { alto } \\
\text { 5- Complexidade técnica: } \\
\text { baixo } \\
\text { 6- Eficiência: baixo }\end{array}$ & $\begin{array}{ll}\text { 1- } & \text { Risco: baixo } \\
\text { 2- } & \text { Custo: Equipe de Marketing } \\
& \text { Junior (US\$ 30.000,00/ano) } \\
\text { 3- } & \text { Gestão: proativa } \\
\text { 4- } & \text { Conhecimento da equipe: } \\
& \text { médio } \\
\text { 5- Complexidade técnica: baixo } \\
\text { 6- Eficiência: alto }\end{array}$ \\
\hline $\begin{array}{l}\text { Gestão de } \\
\text { Mídias Pagas }\end{array}$ & $\begin{array}{l}\text { Compra de mídia } \\
\text { online, otimização } \\
\text { de campanhas e } \\
\text { investimento em } \\
\text { branding. }\end{array}$ & $\begin{array}{ll}\text { 1- } & \text { Risco: baixo } \\
\text { 2- } & \text { Custo: Agência de } \\
& \text { Marketing (20\% do } \\
& \text { investimento em mídias } \\
& \text { pagas) } \\
\text { 3- } & \text { Gestão: passiva } \\
\text { 4- } & \text { Conhecimento da equipe: } \\
& \text { alto } \\
\text { 5- } & \text { Complexidade técnica: alto } \\
\text { 6- } & \text { Eficiência: alto }\end{array}$ & $\begin{array}{ll}\text { 1- } & \text { Risco: baixo } \\
\text { 2- } & \text { Custo: Equipe de Marketing } \\
& \text { Junior (US\$ } 30.000,00 / a n o) \\
\text { 3- } & \text { Gestão: proativo } \\
\text { 4- Conhecimento da equipe: } \\
\text { baixo } \\
\text { 5- Complexidade técnica: alto } \\
\text { 6- Eficiência: médio }\end{array}$ \\
\hline $\begin{array}{l}\text { Design / } \\
\text { Produto }\end{array}$ & $\begin{array}{l}\text { Aperfeiçoamento e } \\
\text { inovação de produto } \\
\text { (website, conteúdo) }\end{array}$ & $\begin{array}{l}\text { 1- Risco: alto } \\
\text { 2- Custo: desenvolvimento e } \\
\text { manutenção (US\$ } \\
\text { 12.000,00/ano) } \\
\text { 3- Gestão: passiva } \\
\text { 4- Conhecimento da equipe: } \\
\text { alto } \\
\text { 5- Complexidade técnica: } \\
\text { 6- Eédia } \\
\text { Eficiência: média }\end{array}$ & $\begin{array}{ll}\text { 1- } & \text { Risco: baixo } \\
\text { 2- } & \text { Custo: desenvolvimento e } \\
\text { manutenção (equipe de UX: } \\
\text { US } \$ 50.000,00 / \text { ano) } \\
\text { 3- } \text { Gestão: proativa } \\
\text { 4- Conhecimento da equipe: } \\
\text { alto } \\
\text { 5- Complexidade técnica: baixo } \\
\text { 6- } & \text { Eficiência: alto }\end{array}$ \\
\hline $\begin{array}{l}\text { Criação de } \\
\text { conteúdos }\end{array}$ & $\begin{array}{l}\text { Elaboração } \\
\text { conteúdos } \\
\text { pedagógicos }\end{array}$ & $\begin{array}{ll}\text { 1- } & \text { Risco: médio } \\
\text { 2- } & \text { Custo: baixo (parceria } \\
& \text { escolas: taxa sobre receita } \\
& \text { bruta mensal) } \\
\text { 3- } & \text { Gestão: passiva } \\
\text { 4- Conhecimento da equipe: } & \text { alto } \\
\text { 5- Complexidade técnica: } \\
\text { baixo } \\
\text { 6- Eficiência: médio }\end{array}$ & $\begin{array}{ll}\text { 1- } & \text { Risco: baixo } \\
\text { 2- } & \text { Custo: alto (equipe } \\
& \text { pedagógica: US\$ } \\
& 50.000,00 / \text { ano) } \\
\text { 3- } & \text { Gestão: proativa } \\
\text { 4- Conhecimento da equipe: } & \text { alto } \\
\text { 5- Complexidade técnica: } \\
\text { media } \\
\text { 6- Eficiência: alto }\end{array}$ \\
\hline
\end{tabular}


Quadro 6 - Processos essenciais da Descomplica

\begin{tabular}{|c|c|c|c|}
\hline Processo & Descrição & Terceirização & Internalização \\
\hline $\begin{array}{l}\text { Produção de } \\
\text { conteúdos }\end{array}$ & $\begin{array}{l}\text { Gravação, edição e } \\
\text { otimização de } \\
\text { conteúdos } \\
\text { pedagógicos }\end{array}$ & $\begin{array}{ll}\text { 1- } & \text { Risco: alto } \\
\text { 2- } & \text { Custo: sob demanda } \\
\text { (produtora: } & \text { US } \$ 100 / \mathrm{h} \text { ) } \\
\text { 3- } & \text { Gestão: passiva } \\
\text { 4- Conhecimento da } & \begin{array}{l}\text { equipe: alto } \\
\text { 5- Complexidade }\end{array} \\
& \text { técnica: baixo } \\
\text { 6- Eficiência: médio }\end{array}$ & $\begin{array}{ll}\text { 1- } & \text { Risco: baixo } \\
\text { 2- } & \text { Custo: alto (ativos imobilizados: } \\
& \text { US\$ 100.000,00; equipe de } \\
& \text { produção e edição: US\$ } \\
& 80.000,00 / \text { ano) } \\
\text { 3- } & \text { Gestão: proativa } \\
\text { 4- } & \text { Conhecimento da equipe: alto } \\
\text { 5- } & \text { Complexidade técnica: baixo } \\
\text { 6- } & \text { Eficiência: alto }\end{array}$ \\
\hline
\end{tabular}

Fonte: elaborado pelos autores.

\section{NOTAS DE ENSINO DO CASO}

\subsection{CURSOS INDICADOS PARA A APLICAÇÃO DO CASO DE ENSINO}

Cursos de graduação e pós-graduação em Administração e Engenharia de Produção ou áreas afins, com ênfase em empreendedorismo, gestão de negócios e startups.

\subsection{DISCIPLINAS INDICADAS PARA A APLICAÇÃO DO CASO DE ENSINO}

A disciplina indicada para aplicação do caso seria a que envolva empreendedorismo, gestão da inovação e gestão de serviços.

\subsection{TEMAS INDICADOS PARA A APLICAÇÃO DO CASO DE ENSINO}

Os temas que se enquadrariam na disciplina de empreendedorismo seriam plano de negócios, análise de SWOT e integração vertical em organizações. Na disciplina Gestão da Inovação, seriam Lean Startup, inovação contínua e desenvolvimento ágil de produtos. Em gestão de serviços, seriam terceirização e internalização de processos.

\subsection{OBJETIVOS DIDÁTICOS DO CASO}

Esse caso de ensino tem por objetivo explorar os conhecimentos e criatividades dos alunos para resolver um dilema real de uma empresa de tecnologia e educação com potencial de atingir milhões de clientes diariamente e ininterruptamente, decidindo sobre quais 
processos podem e/ ou devem ser terceirizados e quais processos são tidos como core competencies da empresa, devendo ficar sob sua gestão. Conhecido no âmbito acadêmico como make or buy decision, a organização, que apresenta um histórico de crescimento exponencial desde sua criação em 2010, necessita garantir a alavancagem do negócio de forma estruturada, prevendo os riscos, benefícios e custos de suas decisões, e também, mantendo seus traços ágeis de startup e qualidade diferenciada no cenário de ensino à distância da educação brasileira.

\subsection{PRÉ-REQUISITOS DOS ALUNOS}

São desejáveis noções de empreendedorismo, planejamento estratégico e gestão da inovação. Em termos específicos, recomendam-se conhecimentos sobre modelagem de negócio, startup enxuta (Lean Startup) e integração vertical.

\subsection{QUESTÕES PARA PREPARAÇÃO}

Como sugestões de questões para preparação do caso pelos alunos:

- Quais processos você classificaria como core business da Descomplica, de acordo com a missão e visão da empresa?

- Quais as vantagens e desvantagens de terceirização de processos em startups ou empresas nascentes?

- Quais as vantagens e desvantagens de internalização de processos em startups ou empresas nascentes?

- Qual a importância de investimento para uma startup que já tenha ganhado tração, ou seja, seu faturamento e aquisição de clientes estão crescendo mensalmente, muito das vezes, por divulgações dos próprios clientes?

- Se você fosse o fundador da Descomplica e tivesse que atingir metas agressivas de faturamento acordadas com seus investidores, você entraria em novos mercados de educação como curso preparatório para concurso público e/ ou preparatório para a prova da OAB? Se sim, quais mercados potenciais você atingiria e por quê? Se não, quais estratégias você usaria para maximizar o faturamento, permanecendo no mercado de estudantes que prestarão o vestibular? 
- Que outros meios de distribuição podem ser utilizados pela empresa Descomplica para democratizar o acesso ao conteúdo educacional?

- Considerando-se a proposta, orçamento e reputação do empreendimento estudado, quais processos da empresa você terceirizaria e quais você internalizaria? Crie uma tabela com aspectos positivos e negativos para cada decisão.

Quadro 7 - Possíveis alternativas e soluções para o dilema do caso

\begin{tabular}{|c|c|c|c|}
\hline Processo & Decisão & Aspectos positivos & Aspectos negativos \\
\hline \multirow[t]{2}{*}{$\begin{array}{l}\text { Validação de } \\
\text { pagamentos online }\end{array}$} & Internalizar & $\begin{array}{l}\text { Total controle perante à } \\
\text { todas as entradas da } \\
\text { empresa; recebimento } \\
\text { em conta bancária } \\
\text { imediato }\end{array}$ & $\begin{array}{l}\text { Passivo em caso de } \\
\text { vazamento de dados } \\
\text { bancários de clientes }\end{array}$ \\
\hline & Terceirizar & $\begin{array}{l}\text { Eliminar passivo em } \\
\text { vazamento de dados } \\
\text { bancários }\end{array}$ & $\begin{array}{l}\text { Comissionamento de } \\
\text { aproximadamente } 5 \% \text { do } \\
\text { faturamento bruto da } \\
\text { empresa; prazo de } \\
\text { recebimento em conta } \\
\text { bancária }\end{array}$ \\
\hline \multirow[t]{2}{*}{ Hospedagem do site } & Internalizar & $\begin{array}{l}\text { Redução de custo de } \\
\text { banda de internet } \\
\text { (upload e streaming de } \\
\text { vídeo) }\end{array}$ & $\begin{array}{l}\text { Alto custo de eletricidade } \\
\text { e manutenção de } \\
\text { hardware; baixa } \\
\text { qualidade, baixa } \\
\text { segurança e baixa } \\
\text { performance }\end{array}$ \\
\hline & Terceirizar & $\begin{array}{l}\text { Reduzir custos de } \\
\text { eletricidade e } \\
\text { manutenção de } \\
\text { hardware; maior } \\
\text { qualidade e segurança de } \\
\text { centros especializados } \\
\text { de processamento de } \\
\text { dados (Datacenter) }\end{array}$ & $\begin{array}{l}\text { Gasto mensal de uso de } \\
\text { infraestrutura; gasto } \\
\text { mensal de banda de } \\
\text { internet por streaming de } \\
\text { vídeo }\end{array}$ \\
\hline \multirow[t]{2}{*}{$\begin{array}{l}\text { Plataforma Web de } \\
\text { conteúdo }\end{array}$} & Internalizar & $\begin{array}{l}\text { Desenvolver } \\
\text { propriedade intelectual; } \\
\text { segurança; }\end{array}$ & $\begin{array}{l}\text { Alto custo com equipe de } \\
\text { TI }\end{array}$ \\
\hline & Terceirizar & $\begin{array}{l}\text { Redução de custo com } \\
\text { plataformas de código } \\
\text { aberto (open source) }\end{array}$ & $\begin{array}{l}\text { Baixa segurança e } \\
\text { dependência }\end{array}$ \\
\hline \multirow[t]{2}{*}{$\begin{array}{l}\text { Suporte ao cliente e/ou } \\
\text { usuário }\end{array}$} & Internalizar & $\begin{array}{l}\text { Melhor qualidade na } \\
\text { comunicação; mais } \\
\text { autonomia na resolução } \\
\text { de problemas; melhores } \\
\text { tempos de resposta }\end{array}$ & $\begin{array}{l}\text { Custo mediano com } \\
\text { equipe de suporte }\end{array}$ \\
\hline & Terceirizar & $\begin{array}{l}\text { Redução de custo } \\
\text { contratando empresas } \\
\text { especializadas em SAC }\end{array}$ & $\begin{array}{l}\text { Baixa autonomia, baixa } \\
\text { eficiência na resolução de } \\
\text { problemas e risco maior } \\
\text { de passivo }\end{array}$ \\
\hline
\end{tabular}


Quadro 7 - Possíveis alternativas e soluções para o dilema do caso

\begin{tabular}{|c|c|c|c|}
\hline Processo & Decisão & Aspectos positivos & Aspectos negativos \\
\hline \multirow[t]{2}{*}{$\begin{array}{l}\text { Gestão de Mídias } \\
\text { Sociais }\end{array}$} & Internalizar & $\begin{array}{l}\text { Desenvolver } \\
\text { propriedade intelectual; } \\
\text { maior autonomia e } \\
\text { interação com a } \\
\text { comunidade }\end{array}$ & $\begin{array}{l}\text { Custo mediano com } \\
\text { equipe de Social Mídia }\end{array}$ \\
\hline & Terceirizar & $\begin{array}{l}\text { Redução de custo } \\
\text { contratando agências } \\
\text { especializadas; uso de } \\
\text { novas tendências }\end{array}$ & $\begin{array}{l}\text { Menos autonomia com a } \\
\text { comunidade, menor } \\
\text { flexibilidade }\end{array}$ \\
\hline \multirow[t]{2}{*}{ Gestão de Mídias Pagas } & Internalizar & $\begin{array}{l}\text { Maior retorno sobre } \\
\text { investimento; mais } \\
\text { flexibilidade em novas } \\
\text { configurações de } \\
\text { campanhas de marketing }\end{array}$ & $\begin{array}{l}\text { Custo mediano com } \\
\text { equipe de Mídia Paga; } \\
\text { baixo uso de novas } \\
\text { tendências de compra de } \\
\text { mídia }\end{array}$ \\
\hline & Terceirizar & $\begin{array}{l}\text { Uso de novas tendências } \\
\text { de compra de mídia e } \\
\text { especialização. }\end{array}$ & $\begin{array}{l}\text { Comunicação prejudicada, } \\
\text { comissionamento sobre } \\
\text { investimento em mídias } \\
\text { pagas }(20 \%)\end{array}$ \\
\hline \multirow[t]{2}{*}{ Design / Produto } & Internalizar & $\begin{array}{l}\text { Desenvolver } \\
\text { propriedade intelectual; } \\
\text { agilidade; flexibilidade }\end{array}$ & $\begin{array}{l}\text { Alto custo com equipe de } \\
\text { design e experiência de } \\
\text { usuário (UX) }\end{array}$ \\
\hline & Terceirizar & $\begin{array}{l}\text { Uso de novas } \\
\text { tendências, redução de } \\
\text { custo em equipe de } \\
\text { design e UX }\end{array}$ & $\begin{array}{l}\text { Baixa flexibilidade e } \\
\text { comunicação prejudicada }\end{array}$ \\
\hline \multirow[t]{2}{*}{ Criação de conteúdos } & Internalizar & $\begin{array}{l}\text { Desenvolver } \\
\text { propriedade intelectual; } \\
\text { maior qualidade; } \\
\text { flexibilidade em novas } \\
\text { configurações }\end{array}$ & $\begin{array}{l}\text { Alto custo com equipe } \\
\text { pedagógica }\end{array}$ \\
\hline & Terceirizar & $\begin{array}{l}\text { Redução de custo com } \\
\text { equipe pedagógica }\end{array}$ & $\begin{array}{l}\text { Menor qualidade e } \\
\text { comunicação prejudicada }\end{array}$ \\
\hline \multirow{2}{*}{$\begin{array}{l}\text { Produção de conteúdos } \\
\text { Produção de conteúdos }\end{array}$} & Internalizar & $\begin{array}{l}\text { Desenvolver } \\
\text { propriedade intelectual; } \\
\text { maior qualidade; } \\
\text { flexibilidade em novas } \\
\text { configurações }\end{array}$ & $\begin{array}{l}\text { Alto custo com equipe de } \\
\text { edição; alto custo com } \\
\text { equipe de gravação; alto } \\
\text { custo com equipamentos e } \\
\text { manutenção }\end{array}$ \\
\hline & Terceirizar & $\begin{array}{l}\text { Redução de custo com } \\
\text { equipe, equipamentos e } \\
\text { manutenção; menor } \\
\text { necessidade gerencial; } \\
\text { maior capacidade de } \\
\text { produção }\end{array}$ & $\begin{array}{l}\text { Menor flexibilidade, } \\
\text { menor criatividade, } \\
\text { custo/hora, }\end{array}$ \\
\hline
\end{tabular}

Fonte: elaborado pelos autores.

\subsection{RECOMENDAÇÕES PARA APLICAÇÃO DO CASO}

A recomendação é que seja um trabalho para o fim do curso, após terem sido passados outros casos mais simples e dos conhecimentos introdutórios e técnicos das disciplinas em questão. 
O professor pode contextualizar o assunto de startups com exemplos de empresas globais como Facebook, Google, Twitter, Coursera e Udemy, apresentando o conceito de organizações escaláveis, modelos de negócio inovadores, capital de risco, retorno de investimento e desenvolvimento ágil.

\subsection{DISCUSSÃO EM SALA DE AULA}

O Professor deve entregar o caso com antecedência para leitura e preparação prévia (pelo menos uma semana). Em sala, os grupos podem ter um tempo de 30 min a 45 min para aprofundarem as discussões e também para ouvirem as dicas e possíveis alternativas do professor. Recomenda-se que os grupos sejam formados por até 04 (quatro) estudantes, para poderem interagir e existir maior sinergia entre os alunos.

Seguindo o formato adotado pelo Método Caso, após a discussão em grupos, os alunos devem se reunir para a discussão em plenária, guiada pelo professor, que irá explorar os aspectos importantes do negócio e levar a turma a refletir em conjunto sobre os prós e contras de cada decisão a ser tomada dos processos. A plenária poderá ocupar até 1 hora da aula.

Outra possibilidade de aplicação do caso é que o professor proponha uma competição entre os grupos, dando mais tempo para o levantamento de dados e informações adicionais. Cada grupo deverá desenvolver e defender a sua alternativa para a turma, que fará uma votação final nas decisões mais fundamentadas. Para aumentar o senso crítico o professor poderia dividir a turma em 2 grandes grupos. Um grupo destacaria e defenderia os pontos fortes da ideia dada pelos alunos que estivessem apresentando seu trabalho, enquanto a outra metade da turma destacaria os pontos fracos, como se fosse um "juri" e assim os alunos aumentariam as noções de gestão e de saberem se posicionar quando são criticados.

Ao final da aula, o professor pode apresentar o que realmente ocorreu com a Descomplica, tomando os devidos cuidados para que os alunos não sintam que suas ideias foram descartadas (Quadro 8). No Método Caso o processo de construção do conhecimento é tão importante quanto seus resultados.

A Descomplica, consolidando-se como uma empresa de educação e tecnologia, e buscando se tornar uma organização de referência mundial no setor de educação, apostou em desenvolver ao máximo sua propriedade intelectual. Processos estratégicos da empresa que envolviam as duas principais core competencies do negócio - educação e tecnologia - foram priorizados para serem feitos internamente, preservando a autoria, qualidade, agilidade e eficácia. 
Quadro 8 - Como a Descomplica solucionou o problema

\begin{tabular}{|c|c|c|c|}
\hline Processo & Decisão & Aspectos positivos & Aspectos negativos \\
\hline $\begin{array}{ll}\text { Validação } & \text { de } \\
\text { pagamentos online }\end{array}$ & Terceirizar & $\begin{array}{lcr}\text { Eliminar } & \text { passivo } & \text { em } \\
\text { vazamento } & \text { de } & \text { dados } \\
\text { bancários } & & \end{array}$ & $\begin{array}{lcr}\text { Comissionamento } & \text { de } \\
\text { aproximadamente } 5 \% & \text { do } \\
\text { faturamento } & \text { bruto } & \text { da } \\
\text { empresa; } & \text { prazo } & \text { de } \\
\text { recebimento } & \text { em conta } \\
\text { bancária } & & \end{array}$ \\
\hline Hospedagem do site & Terceirizar & $\begin{array}{lr}\text { Reduzir custos } & \text { de } \\
\text { eletricidade } & \mathrm{e} \\
\text { manutenção de hardware; } & \text { maior qualidade } \mathrm{e} \\
\text { segurança de centros } \\
\text { especializados } & \text { de } \\
\text { processamento de } & \text { dados } \\
\text { (Datacenter) } & \\
\end{array}$ & $\begin{array}{l}\text { Gasto mensal de uso de } \\
\text { infraestrutura; gasto } \\
\text { mensal de banda de } \\
\text { internet por streaming de } \\
\text { vídeo }\end{array}$ \\
\hline $\begin{array}{l}\begin{array}{l}\text { Plataforma } \\
\text { conteúdo }\end{array} \\
\text { Web de }\end{array}$ & Internalizar & $\begin{array}{l}\text { Desenvolver propriedade } \\
\text { intelectual; segurança; }\end{array}$ & $\begin{array}{l}\text { Alto custo com equipe de } \\
\text { TI }\end{array}$ \\
\hline $\begin{array}{l}\text { Suporte ao cliente e/ou } \\
\text { usuário }\end{array}$ & Internalizar & $\begin{array}{l}\text { Melhor qualidade na } \\
\text { comunicação; mais } \\
\text { autonomia na resolução } \\
\text { de problemas; melhores } \\
\text { tempos de resposta }\end{array}$ & $\begin{array}{l}\text { Custo mediano com equipe } \\
\text { de suporte }\end{array}$ \\
\hline $\begin{array}{lll}\text { Gestão } & \text { de } & \text { Mídias } \\
\text { Sociais } & & \end{array}$ & Internalizar & $\begin{array}{lr}\text { Desenvolver } & \text { propriedade } \\
\text { intelectual; } & \text { maior } \\
\text { autonomia e interação } \\
\text { com a comunidade }\end{array}$ & $\begin{array}{l}\text { Custo mediano com equipe } \\
\text { de Social Mídia }\end{array}$ \\
\hline Gestão de Mídias Pagas & Internalizar & $\begin{array}{lr}\text { Maior retorno } & \text { sobre } \\
\text { investimento; } & \text { mais } \\
\text { flexibilidade em } & \text { novas } \\
\text { configurações } & \text { de } \\
\text { campanhas de marketing }\end{array}$ & $\begin{array}{l}\text { Custo mediano com equipe } \\
\text { de Mídia Paga; baixo uso } \\
\text { de novas tendências de } \\
\text { compra de mídia }\end{array}$ \\
\hline Design / Produto & Internalizar & $\begin{array}{l}\text { Desenvolver } \\
\text { intelectual; } \\
\text { flexibilidade }\end{array}$ & $\begin{array}{l}\text { Alto custo com equipe de } \\
\text { design e experiência de } \\
\text { usuário (UX) }\end{array}$ \\
\hline Criação de conteúdos & Internalizar & $\begin{array}{lr}\text { Desenvolver } & \text { propriedade } \\
\text { intelectual; } & \text { maior } \\
\text { qualidade; } & \text { flexibilidade } \\
\text { em novas configurações }\end{array}$ & $\begin{array}{l}\text { Alto custo com equipe } \\
\text { pedagógica }\end{array}$ \\
\hline Produção de conteúdos & Internalizar & $\begin{array}{lr}\text { Desenvolver } & \text { propriedade } \\
\text { intelectual; } & \text { maior } \\
\text { qualidade; } & \text { flexibilidade } \\
\text { em novas configurações }\end{array}$ & $\begin{array}{l}\text { Alto custo com equipe de } \\
\text { edição; alto custo com } \\
\text { equipe de gravação; alto } \\
\text { custo com equipamentos e } \\
\text { manutenção }\end{array}$ \\
\hline
\end{tabular}

Fonte: elaborado pelos autores.

Não se pode negar que a obtenção de um investimento milionário para a aceleração do crescimento da empresa foi um fator relevante para desenvolver a identidade da Descomplica, optando por processos de realização interna que muitos dos quais poderiam ter sido terceirizados, a fim de manter uma equipe enxuta e uma estrutura de custo menor.

Outro fator importante na tomada de decisão é a cultura de inovação contínua na empresa que, através de metodologias ágeis de desenvolvimento, buscava-se inovar seus produtos e processos de forma recorrente, como estratégia competitiva. A aquisição de ativos 
e a contratação de equipes adjacentes aos objetivos centrais da empresa promoveu uma maior flexibilidade e eficiência em experimentações, que permitiram o acúmulo de aprendizados traduzindo-os em novas competências para a empresa.

No último trimestre de 2012, a Descomplica recebeu seu primeiro aporte milionário de fundos americanos de capital de risco no valor aproximado de US\$2.000.000,00, tornando-se viável seu plano de expansão e internalizando os seguintes processos: distribuição de conteúdo através de uma plataforma web; atendimento ao cliente; gestão de mídias sociais; gestão de mídias pagas; desenvolvimento do design / produto; criação e produção de conteúdos.

Apesar de a empresa ter atuado com despesas operacionais que superavam a receita, a aposta ambiciosa em se tornar a maior plataforma de educação mundial estava no percurso certo. O jeito de aprender de forma divertida e descontraída da empresa contribuiu para o aprimoramento de 12 milhões de estudantes nos dois anos seguinte ao aporte milionário, posicionando-se como uma das maiores empresas de educação e tecnologia do mundo.

Algumas empresas de tecnologia e educação apostaram na terceirização e/ ou parceria de alguns processos-chaves para alavancar seus negócios. No caso da Udemy, fundada por Eren Bali, em 2010, a empresa terceirizou a produção de conteúdo para os próprios usuários, gerando um market place de professores e estudantes.

A empresa Coursera, fundada por Andrew Ng e Daphne Koller em 2012, utilizaram a parceria como estratégia de produção de conteúdo, fechando acordo inicialmente com mais de 17 universidades renomadas para criação de cursos online de qualidade.

Já a ONG educacional Khan Academy, fundada por Salman Kahn em 2014, utiliza a colaboração financeira de pessoas e empresas para custear a produção de conteúdos educacionais na área da matemática. A Fundação Lemann, do empresário brasileiro Jorge Paulo Lemann, é uma das empresas que investiu na ideia com um aporte milionário.

\section{REFERÊNCIAS SUGERIDAS PARA APOIAR A ANÁLISE DO CASO}

BAUFOUR, Brian. Essay - Traction vs Growth. Disponível em:

http://www.coelevate.com/essays/traction-vs-growth. Acesso em: 4 ago. 2015.

BLANK, S. DORF, B. Startup: manual do empreendedor. Tradução da $1^{a}$ edição. Rio de Janeiro: Alta Books: 2015.

CGTN AMERICA. Brazilian education sees successful e-learning business startup.

Disponível em: http://www.cctv-america.com/2015/09/30/brazilian-education-sees- 
successful-e-learning-business-startup. Acesso em: 15 set. 2015.

DESCOMPLICA. Canal do Descomplica no Youtube. (disponível em:

https://www.youtube.com/user/sitedescomplica). Acesso em: 11 out. 2015.

ÉPOCA NEGÓCIOS. Investidor do Facebook vira sócio de empresa criada por professor brasileiro Disponível em:

http://epocanegocios.globo.com/Inspiracao/Empresa/noticia/2012/12/investidor-do-facebookvira-socio-de-empresa-criada-por-professor-brasileiro.html. Acesso em: 07 jul 2015.

ESCOLAS MÉDICAS DO BRASIL. Valores das Mensalidades dos Cursos de Medicina

Privados. Disponível em: http://www.escolasmedicas.com.br/mensal.php. Acesso em: 11 out. 2015.

FORAS DE SÉRIE. Sala de aula virtual. Disponível em:

http://www.forasdeserie.com/episodio/marco-fisbhen. Acesso em: 7 jun. 2015.

GUIA DO ESTUDANTE. Cursinhos no Brasil. Disponível em:

http://guiadoestudante.abril.com.br/vestibular-enem/cursinhos. Acesso em: 11 out. 2015.

GUTWALD, P. M. Strategic outsourcing and technology supply chains. Master's thesis

(Management). Massachusetts: MIT, 1995.

INEP - INSTITUTO NACIONAL DE ESTUDOS E PESQUISAS EDUCACIONAIS

ANÍSIO TEIXEIRA. IDEB Resultados. Disponível em: http://ideb.inep.gov.br/resultado.

Acesso em: 28 out. 2017.

INEP - INSTITUTO NACIONAL DE ESTUDOS E PESQUISAS EDUCACIONAIS

ANÍSIO TEIXEIRA Sinopses Estatísticas da Educação Básica. Disponível em:

http://inep.gov.br/sinopses-estatisticas-da-educacao-basica. Acesso em: 28 out. 2017.

JORDAN, J., HARIHARAN, A., CHEN, F., KASIREDDY, P. 16 Startup Metrics.

Disponível em: http://a16z.com/2015/08/21/16-metrics/. Acesso em: 22 out. 2015.

LAVCA VENTURE INVESTORS. Gávea Angels reaches exit, a first for an angel

investor network in Brazil. Disponível em: http://lavca.org/2011/08/16/gavea-angels-

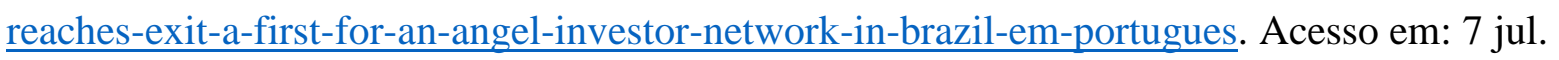

2015.

MAN IN THE AREA. Masco Fisbhen (Descomplica). Disponível em:

https://youtu.be/d5H89tadlrY. Acesso em: 25 mar. 2015.

NIGRI, M. R. MONTEIRO, P. V. C. Estudo de caso da aplicação do customer

development a uma startup digital de educação. Monografia (Graduação em Engenharia de

Produção). Rio de Janeiro: Escola Politécnica/ UFRJ, 2014.

OSTERWALDER, A. PIGNEUR, Y. Business model generation: inovação em modelos de 
negócios. Tradução da $1^{\mathrm{a}}$ edição. Rio de Janeiro: Alta Books, 2011.

PEQUENAS EMPRESAS GRANDES NEGÓCIOS. Descomplica recebe segunda rodada de investimentos. Disponível em:

http://revistapegn.globo.com/Noticias/noticia/2014/02/descomplica-recebe-segunda-rodadade-investimentos.html. Acesso em: 6 jun. 2015 .

PICHLER, R. Gestão de processos com Scrum - implementando métodos ágeis na criação e desenvolvimento de produtos. Rio de Janeiro: Campus/ Elsevier, 2011.

QUINN, James B.; HILMER, Frederick G. Strategic outsourcing. Sloan Management.

Review, v. 35, n. 4, pp. 43-55, 1994.

RIES, E. A startup enxuta. Tradução da $1^{a}$ edição. São Paulo: Leya, 2012.

ROCKET COMPANIES. Education startups - the fastest growing in the last year.

Disponível em: http://www.rocketcompanies.com/reports/education-startups. Acesso em: 7 jun. 2015.

SERIO, L. C. D., SAMPAIO, M. Projeto da cadeia de suprimento: uma visão dinâmica da decisão fazer versus comprar. Revista de Administração de Empresas, v.41, n.1, pp. 5466, 2001.

TECHCRUNCH. Why Ed Tech is taking off in Latin America. Disponível:

http://techcrunch.com/2015/07/11/why-ed-tech-is-taking-off-in-latin-america. Acesso em: 14 ago. 2015

TECHCRUNCH. Is For-Profit The Future Of Education In Brazil? Disponível em: http://techcrunch.com/2015/07/19/is-for-profit-the-future-of-education-in-brazil. Acesso em: 26 set. 2015.

THE NEXT WEB. 12 Latin American startups to look out for in 2014. Disponível em: http://thenextweb.com/la/2013/12/28/12-latin-american-startups-look-2014. Acesso em: 28 jun. 2015.

THINK WITH GOOGLE. Think education with Google. Disponível em:

https://www.thinkwithgoogle.com/intl/pt-br/articles/think-education-with-google-Q3-

2013.html. Acesso em: 2 abr. 2015.

VALOR ECONÔMICO. Site de aulas on-line, Descomplica recebe novo aporte.

Disponível em: http://www.valor.com.br/empresas/4091074/site-de-aulas-line-descomplicarecebe-novo-aporte. Acesso em: 13 set. 2015. 


\section{APÊNDICE 1 - LISTA DE MATÉRIAS PUBLICADAS SOBRE A DESCOMPLICA}

\begin{tabular}{|c|c|c|c|}
\hline Ano & Título da Matéria & $\begin{array}{l}\text { Veículo de } \\
\text { Publicação }\end{array}$ & País \\
\hline \multirow{5}{*}{2015} & Why Ed Tech Is Taking Off In Latin America & TechCrunch & EUA \\
\hline & $\begin{array}{l}\text { Brazilian education sees successful e-learning } \\
\text { business startup }\end{array}$ & CCTV America & EUA \\
\hline & Is For-Profit The Future Of Education In Brazil? & TechCrunch & EUA \\
\hline & Descomplica recebe 21 milhões em novo aporte & Infomoney & BR \\
\hline & Case 2014 - Marco Fisbhen (Descomplica) & Man in the Area & BR \\
\hline \multirow{6}{*}{2014} & $\begin{array}{l}\text { Education Startups - The fastest growing in the } \\
\text { last year }\end{array}$ & Rocket Companies & EUA \\
\hline & Marco Fisbhen: Sala de aula virtual & Foras de Série & BR \\
\hline & $\begin{array}{l}\text { Descomplica recebe segunda rodada de } \\
\text { investimento }\end{array}$ & Globo.com & $\mathrm{BR}$ \\
\hline & Think Education with Google & Think With Google & EUA \\
\hline & Man in the Area - Marco Fisbhen & Man in the Area & BR \\
\hline & $\begin{array}{l}\text { 12 Latin American startups to look out for in } \\
2014\end{array}$ & The Next Web & Holanda \\
\hline \multirow{2}{*}{2012} & $\begin{array}{l}\text { Marco Fisbhen, do Descomplica, dá dicas para } \\
\text { empreendedores }\end{array}$ & Globo.com & $\mathrm{BR}$ \\
\hline & $\begin{array}{l}\text { Investidor do Facebook vira sócio de empresa } \\
\text { criada por professor brasileiro. }\end{array}$ & Globo.com & $\mathrm{BR}$ \\
\hline 2011 & $\begin{array}{l}\text { Gávea Angels Reaches Exit, a First for an Angel } \\
\text { Investor Network in Brazil }\end{array}$ & Lavca & EUA \\
\hline
\end{tabular}

\section{APÊNDICE 2 - LINKS COM REPORTAGENS SOBRE A DESCOMPLICA E SEU FUNDADOR}

De maneira complementar, para fins de melhor fundamentação no caso em tela, sugere-se ao docente que navegue pelos links das respectivas reportagens e matérias sobre a Descomplica e seu fundador:

\section{5:}

http://www.cctv-america.com/2015/09/30/brazilian-education-sees-successful-e-learningbusiness-startup

http://techcrunch.com/2015/07/11/why-ed-tech-is-taking-off-in-latin-america/

http://techcrunch.com/2015/07/19/is-for-profit-the-future-of-education-in-brazil/

http://startse.infomoney.com.br/portal/2015/06/12/12294/descomplica-recebe-r-21-milhoesem-novo-aporte/

Canal Man in the Area no Youtube: https://youtu.be/ah86fs8noaI

\section{4:}

http://www.forasdeserie.com/episodio/marco-fisbhen

http://www.rocketcompanies.com/reports/education-startups/

http://revistapegn.globo.com/Noticias/noticia/2014/02/descomplica-recebe-segunda-rodada- 
de-investimentos.html

\section{3:}

https://www.thinkwithgoogle.com/intl/pt-br/articles/think-education-with-google-Q32013.html

Canal Man in the Area no Youtube: https://youtu.be/d5H89tadlrY

http://thenextweb.com/la/2013/12/28/12-latin-american-startups-look-2014/

\section{2:}

http://globotv.globo.com/editora-globo/movimento-empreenda/v/marco-fisbhen-dodescomplica-da-dicas-para-empreendedores/2099093/

http://epocanegocios.globo.com/Inspiracao/Empresa/noticia/2012/12/investidor-do-facebookvira-socio-de-empresa-criada-por-professor-brasileiro.html

\section{1:}

http://lavca.org/2011/08/16/gavea-angels-reaches-exit-a-first-for-an-angel-investor-networkin-brazil-em-portugues 